\title{
Flood Hazard Mapping with Distributed Hydrological Simulations and Remote-Sensed Slackwater Sediments in Ungauged Basins
}

\author{
José David del Moral-Erencia ${ }^{1}\left(\mathbb{D}\right.$, Patricio Bohorquez ${ }^{1,2, *(\mathbb{C})}$, Pedro Jesus Jimenez-Ruiz ${ }^{2}$ (i) \\ and Francisco José Pérez-Latorre ${ }^{3}$ (I) \\ 1 Centro de Estudios Avanzados en Ciencias de la Tierra, Energía y Medio Ambiente, Universidad de Jaén, \\ Campus Las Lagunillas, 23071 Jaén, Spain; jdmoral@ujaen.es \\ 2 Área de Mecánica de Fluidos, Dpto Ingeniería Mecánica y Minera, Universidad de Jaén, Campus Las \\ Lagunillas, 23071 Jaén, Spain; pjruiz@ujaen.es \\ 3 Área de Mecánica de Fluidos, Dpto Ingeniería Mecánica y Minera, Universidad de Jaén, Campus Científico \\ Tecnológico de Linares, 23700 Linares, Spain; fjperez@ujaen.es \\ * Correspondence: patricio.bohorquez@ujaen.es; Tel.: +34-953-212872
}

\section{check for}

updates

Citation: del Moral-Erencia, J.D.; Bohorquez, P.; Jiménez-Ruiz, P.J.; Pérez-Latorre, F.J. Flood Hazard Mapping with Distributed Hydrological Simulations and Remote-Sensed Slackwater Sediments in Ungauged Basins. Water 2021, 13, 3434. https://doi.org/10.3390/ w13233434

Academic Editors: Philippe Paillou and Troy Sternberg

Received: 30 October 2021

Accepted: 1 December 2021

Published: 3 December 2021

Publisher's Note: MDPI stays neutral with regard to jurisdictional claims in published maps and institutional affiliations.

Copyright: (c) 2021 by the authors. Licensee MDPI, Basel, Switzerland. This article is an open access article distributed under the terms and conditions of the Creative Commons Attribution (CC BY) license (https:/ / creativecommons.org/licenses/by/ $4.0 /)$.

\begin{abstract}
We present a basin-scale method to assimilate hydrological data from remote-sensed flood evidence and map civil infrastructures with risk of flooding. As in many rural areas with a semi-arid climate, the studied catchments do not contain stream gauge, and precipitation data does not capture the spatial variability of extreme hydrological events. Remote-sensed flood evidence as slackwater sediments were available at the whole basin, allowing the paleohydrological reconstruction at many sites across the catchment. The agreement between the predicted and observed inundation area was excellent, with an error lower than $15 \%$ on average. In addition, the simulated elevations overlapped the observed values in the flooded areas, showing the accuracy of the method. The peak discharges that provoked floods recorded the spatial variability of the precipitation. The variation coefficients of the rainfall intensity were $30 \%$ and $40 \%$ in the two studied basins with a mean precipitation rate of 3.1 and $4.6 \mathrm{~mm} / \mathrm{h}$, respectively. The assumption of spatially uniform precipitation leads to a mean error of $20 \%$ in evaluating the local water discharges. Satellite-based rainfall underpredicted the accumulated precipitation by $30-85.5 \%$. Elaborating an inventory of the civil infrastructures at risk was straightforward by comparing the water surface elevation and transport network. The reconstructed maps of rainfall rate were used in the distributed hydrological model IBERPLUS to this end. Recent flood events that overtopped the infrastructures at risk verified our predictions. The proposed research methods can be easily applied and tested in basins with similar physical characteristics around the Mediterranean region.
\end{abstract}

Keywords: paleohydrology; short-rain flood; distributed hydrological model; slackwater sediments; flood risk mapping

\section{Introduction}

Both the frequency and magnitude of pluvial floods with a duration lower than one day have increased during the last decade in the southern Mediterranean area of Spain (see Moral-Erencia et al. [1]), corroborating the predictions of the Intergovernmental Panel on Climate Change [2] and the European Environmental Agency [3]. The study of such type of extreme hydrological event, referred from now on as short-rain flood [4], is becoming more and more relevant in many Mediterranean areas of Europe [5].

Short-rain floods are hazardous in regions affected by climate change with increasing rainfall intensities if soil use and management prevent infiltration [6]. The runoff depths are deeper than expected across the whole drainage basin, increasing, therefore, the risk of flooding. So, areas at flood risk might not be limited to the floodplains of the main river 
but extend over tributary sub-basins and their drainage network (e.g., torrents and gullies). Distributed hydrological models based on the two-dimensional Saint-Venant equations can be adopted for flood hazard mapping at such a spatial scale [7-9]. Outstanding free software accelerated by multi-CPU and graphics processing unit (GPU) emerged in the last decade [10]. More recently, IBERPLUS [11], SERGHEI-SWE [12], TRITON [13] and LISFLOOD-FP [14]. Such distributed hydrological models use a physical-based approach to simulate complex physical processes leading to runoff, routing the water through all the elements of the drainage network, and generating even flood maps.

This work is motivated by the need to overcome a series of difficulties intrinsic to flood hazard analysis of small ungauged basins suffering from extreme short-rainfall events. First, rainfall-runoff simulations are not plausible in small semiarid catchments $\left(<2000 \mathrm{~km}^{2}\right)$ because of the low rain gauge density, see Pilgrim et al. [15]. Second, the time resolution of a great number of existing rainfall databases (e.g., AEMET [16], Spain02 [17], IMERG [18], TRMM [19], among others) is inadequate to capture the actual magnitude of sub-daily events like flash floods (event duration of $T<1.5 \mathrm{~h}$ ) and short-rain floods $(1.5<T<24 \mathrm{~h}$ ). Even hourly satellite databases (CMORPH [20], GSMaP [21], PersiannCCS and PDIR-Now [22]) are based on sampling frequencies of $12 \mathrm{~h} \mathrm{[23],} \mathrm{using} \mathrm{out} \mathrm{of}$ phase interpolation techniques for increasing the sampling time [24]. On the one side, databases of maximum one-day precipitation are useful for flood risk mapping associated with continuous rainfalls of $>7$ days [25], referred to as long-rain floods [4]. On the other side, the low density and the temporal resolution of the gauges network and geostationary orbits of satellites prevent the characterisation of runoff and floods caused by reduced-size storms and short-rain events, see Notti et al. [26], which is the topic of this paper.

A first novelty of the method developed in this paper is the use of high-resolution post-flood satellite imagery ( $<1 \mathrm{~m}$, e.g., WorldView-2 and GeoEye-1) to account for the paleoclimatic significance of geomorphic evidence, which is proof of a change in the hydrologic variables of runoff and sediment yield [27]. Post-event evidence as slackwater sediments record the extension of the inundated areas in catchments with a large sediment budget, see Bohorquez [28]. In this study, we show for the first time that such images allow the delimitation of slackwater sediments among other flood evidence at the basin scale. Unmanned aerial vehicles, in addition, allow for mapping geomorphological features of sediment deposits to assess flood hazards [29-31]. The extent of the inundated areas and the water levels can be determined by getting the altimetry of the shorelines from LiDAR elevations. Indeed, Bohorquez and Moral-Erencia [32] verified the accuracy of such an approach and reported errors in water elevation lower than $5 \%$ relative to the flood depth from detailed field observations and GPS survey.

A second advance is a method to infer the water discharge based on maximising the Critical Success Index $[33,34]$ of the remote-sensed flood extent with respect to the simulated inundation with the hydraulic module of IBERPLUS [11]. The method is an alternative to minimising the error of the simulated water level concerning the position of paleostage indicators (PSIs) identified in field works [35-37]. The incorporation of remotesense identification of paleoflood stage complements other data source as high-water marks (HWMs) [38], historical [39], botanical [40], geological paleostage indicators [41], groundpenetrating radar profiles [42] and dendrogeomorphic analyses [43]. Then, the geographical distribution of the precipitation can be derived from the reconstructed peak discharges using the rational method [1,44], a physical-based approach [45] or intricate hydrological simulations [46].

The paper is organised as follows: Materials and Methods are described in Section 2. The detailed numerical results are explained in Section 3. First, we focus on verifying the hydrological calculation with a uniform rainfall, drawing essential conclusions on the computed hydrograph (Section 3.1). Later, we evaluate the accuracy of the new method based on reconstructing the geographical distribution of the precipitation (Section 3.2). Then, we verify the new approach in terms of water elevations (Section 3.3) and discuss the validity of rainfall databases. Lastly, we draw some conclusions in Section 4. 


\section{Materials and Methods}

\subsection{Study Site}

The study site encompasses two tributary drainage basins of the Guadalquivir river (SE Spain): Salado de Porcuna and Salado de Arjona, referred to as BI and BII in Figure 1, respectively. For the sake of conciseness, we provide a summary of the main characteristics and refer the reader to Moral-Erencia et al. [1] for extra details.
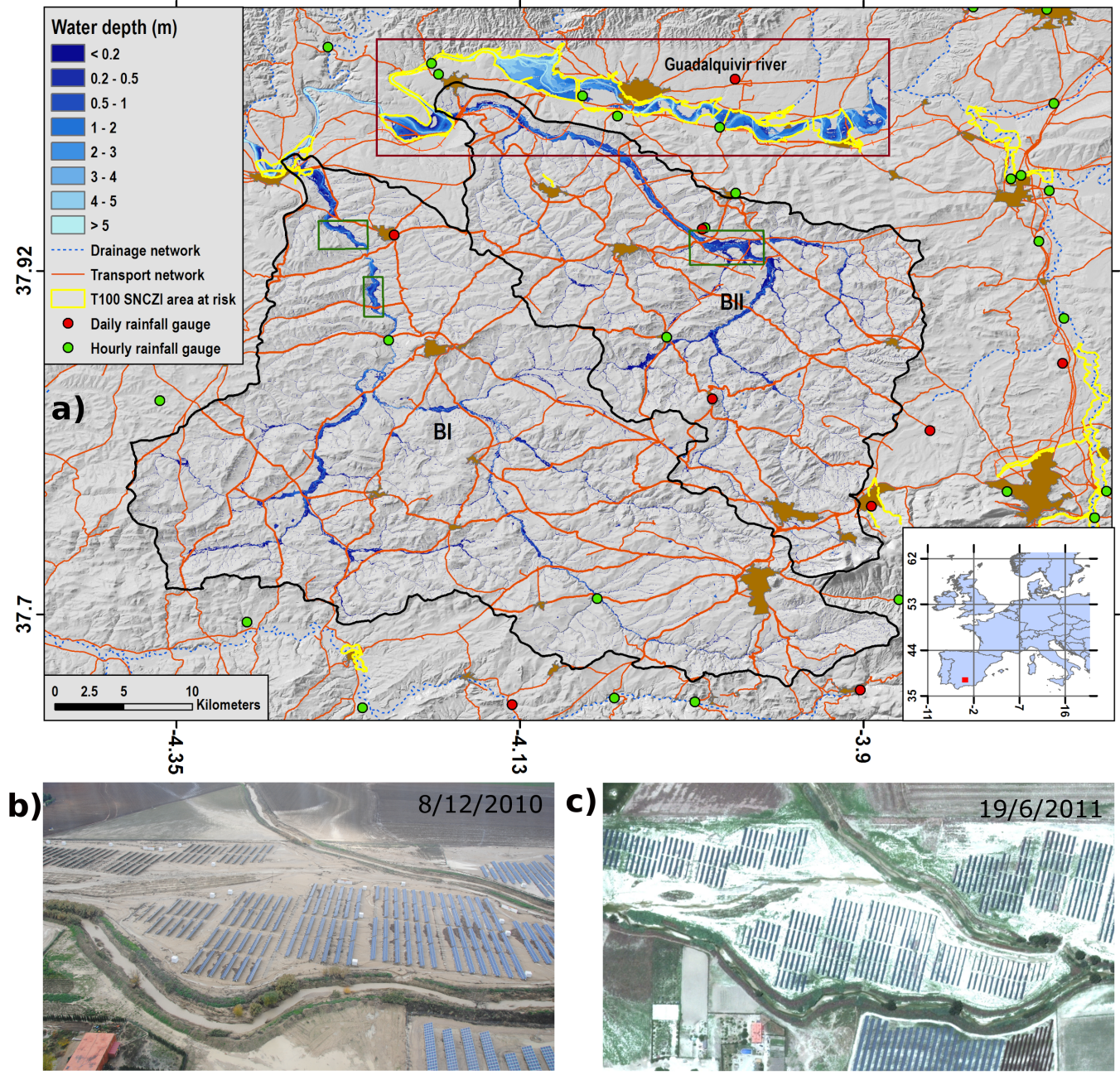

Figure 1. (a) The map shows the tributary basins BI and BII (perimeter in solid black line) of the Guadalquivir River in southern Spain (see location at the inset) analysed in this work and the existing rainfall gauges with a daily (red dots) and hourly (green dots) sample frequency. For completeness, the largest rectangle in brown depicts the area of the Guadalquivir river where we studied long-rain floods [28,32], and the three rectangles in green inside BI-BII locate the river stretches in which we reported preliminary results for short-rain floods [1]. Yellow contours represent the $100 \mathrm{yr}$ flood-prone areas defined by the Spanish Government according to the EU Directive 2007/60 on the estimation and management of flood risk [47]. Finally, the computed flooding map at the catchment scale is shown in blue. (b) Helicopter photograph taken one day after the flood showing an example of slackwater sediments deposited in the inundated areas. (c) Satellite imagery six months after the flood showing the same slackwater sediments as in panel c, as well as young grass in the wetter perimeter of the inundated areas.

In the Guadalquivir basin, we can distinguish two kinds of precipitation or floods events. First, long-rain floods during continuous rainfalls of $>7$ days which extensively inundate the floodplains of the main Guadalquivir river but only occasionally impact the tributary basins, as shown by Bohorquez [28] and Bohorquez and Moral-Erencia [32]. 
Second, short-rain floods due to intense storms with a duration between 1.5 and $24 \mathrm{~h}$. The latter occurs in steep sub-basins of the upper reach of the Guadalquivir river, mouth to the south [1]. In the last decade, short-rain floods developed mostly every year overtopping, for instance, the road transport network with concurrent damages and economic loss [48]. Daily floods occurred in 1996, 1999, 2001, 2003, 2007, 2008, 2009, 2012, 2016, 2018 and 2019.

In the present study, we focus on the December 2009 short-rain flood that occurred in the tributary basins of the Guadalquivir river shown in Figure 1. It represents the second largest-magnitude event since 1985. However, details of the precipitation intensity and duration are unknown because the distance to the nearest meteorological radars, see Figure 2, provoked a non-optimal coverage of the radar samples and the infra-estimation of the stratiform winter precipitation [49]. In addition, the rain gauges have a low density (see their locations in Figure 1). They do not capture the great spatial variations of rainfall, impeding the computation of the runoff production. The soil saturation condition attained after the continuous rains of previous weeks $[16,17]$ aggravated the intensity of the local precipitation event. According to the duration of the rising $\operatorname{limb}(7.5 \mathrm{~h})$ and the plateau stage at peak flow $(3 \mathrm{~h})$ of the hydrograph at the outlet of $\mathrm{BI}$, the extreme rainstorm lasted about $10.5 \mathrm{~h} \mathrm{[1].}$
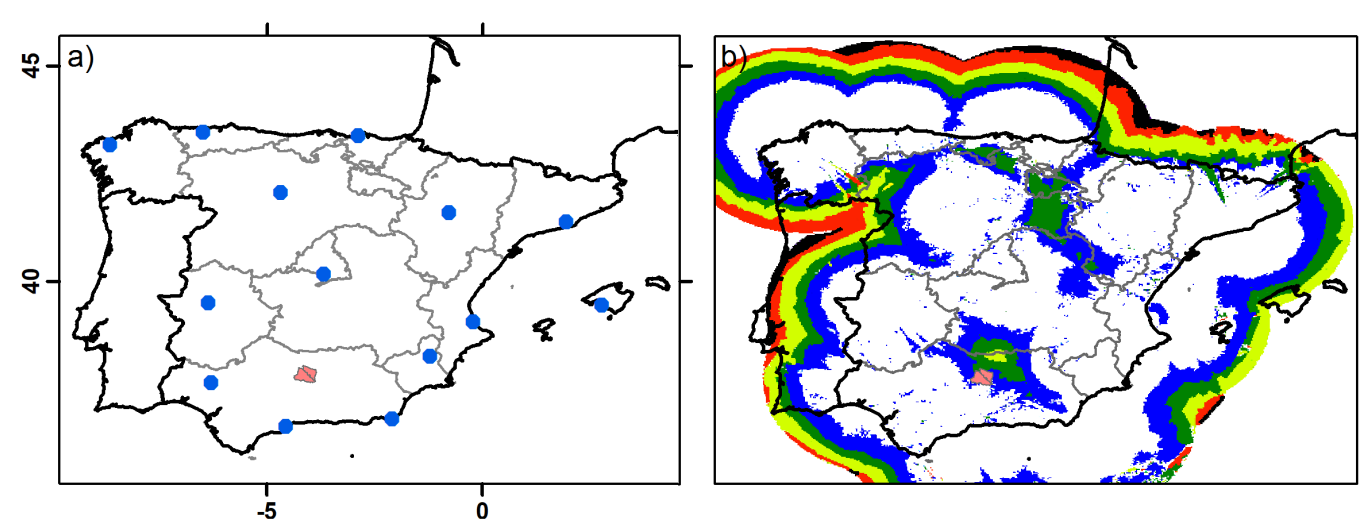

Figure 2. (a) Location of the meteorological radars of the Spanish Meteorological Agency. We indicate the position of the study basins with a pink colour, being the nearest radar to $160 \mathrm{~km}$. (b) Colour gradient indicates the range of the meteorological radar network. Note that the study basins (in pink colour) do not exhibit an optimal scope.

The whole study area amounts to $1300 \mathrm{~km}^{2}$, being BI $\left(810 \mathrm{~km}^{2}\right)$ larger than BII $\left(490 \mathrm{~km}^{2}\right)$. The Guadalquivir depression and the Baetic mountain chain lend steep-slope conditions $(>8 \%)$ to the study basins (Figure 3a). The soil is dedicated mostly to olive groves with traditional use $(>85 \%)$, see Figure $3 c$, i.e., the vegetation that surrounds the crops was removed. In combination with the steep slope, the conventional tillage caused intense laminar and gully erosion processes through time. Soil degradation also. The flow regime in the gullies, torrents and main river channel was unaltered because of the lack of dams in both basins. Hence, intense precipitations yield floods, as they should be. To conclude, the most representative geomorphological data are as follows: the average thalweg slope is $1 \%$, leading to a transcritical flow regime during the floods; the characteristic bankfull depth is around $3 \mathrm{~m}$ in both basins; bankfull width is about $40 \mathrm{~m}$ in BI and $27 \mathrm{~m}$ in BII; and, the floodplains are well-developed in the intermediate and lower stretches of both catchments, with a characteristic width of 243-470 m in BI and 198-660 m in BII. All these features provoked the deposition of slackwater sediments in numerous areas of low flow velocity. 

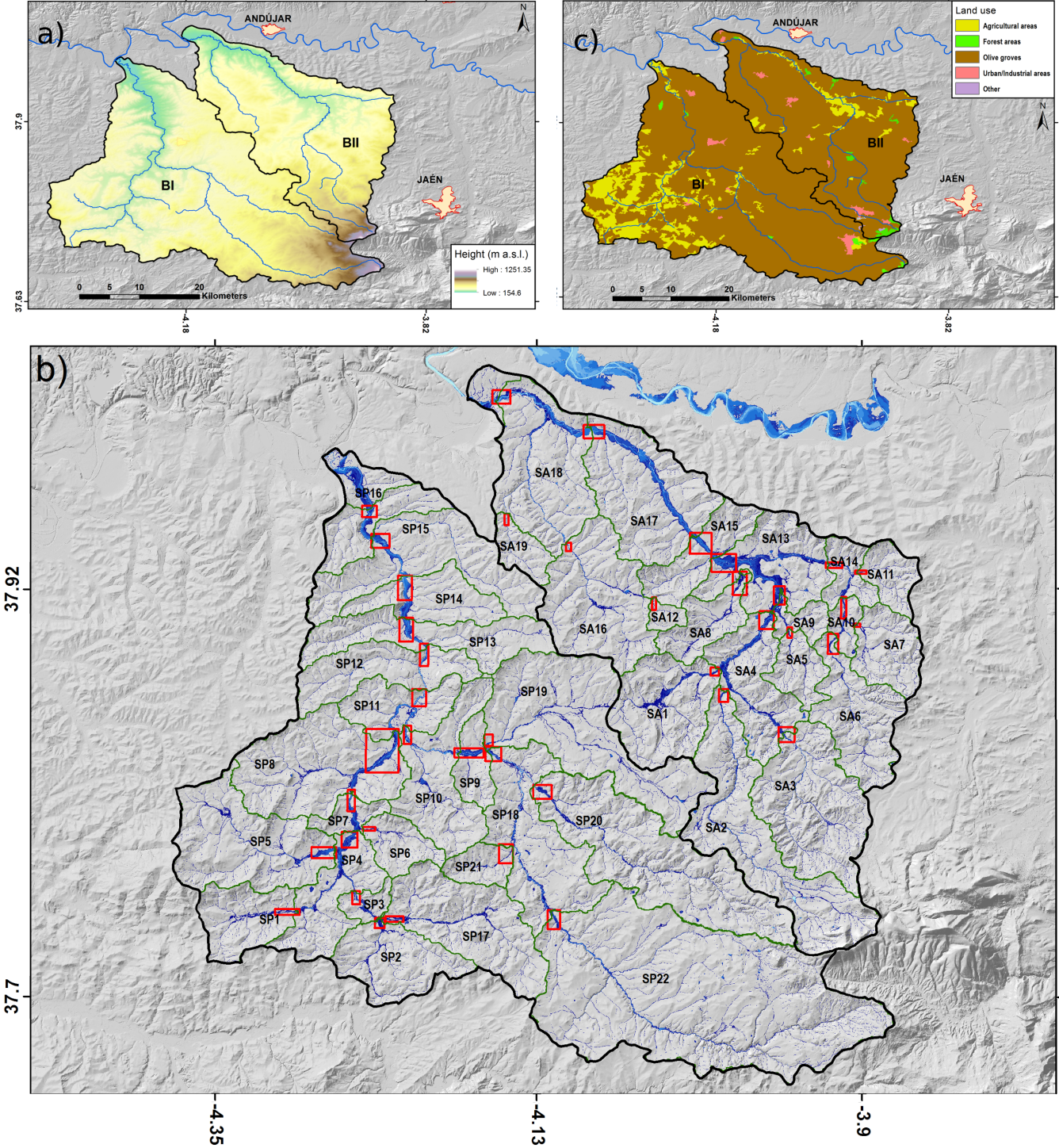

Figure 3. (a) Hypsometric map of the studied basins.(b) Delimitation of the river stretches used in the recursive paleohydrological reconstruction. (c) Land use map.

\subsection{Methodology}

The methodology includes a direct (red arrows) and inverse (black arrows) method sketched in Figure 4. Such approaches combine different techniques of paleohydraulics, remote sensing and computational fluid dynamics. Next, we give a description of the underlying stages.

\subsubsection{Direct Method: Hydrological Calculation with Uniform Precipitation}

In the last decades, the application of distributed hydrological models has increased $[9,11-14]$ due to the speedup of the numerical simulations using GPU [10]. Here we combine the modelling of rainfall-runoff processes through a feedback loop with paleohydrology. We used the distributed hydrological model IBERPLUS [11] to simulate the rainfall-runoff-flood processes in the two basins BI and BII by setting the reconstructed Probable Maximum Rainfall (PMR) in Moral-Erencia et al. [1] as the input parameter. 


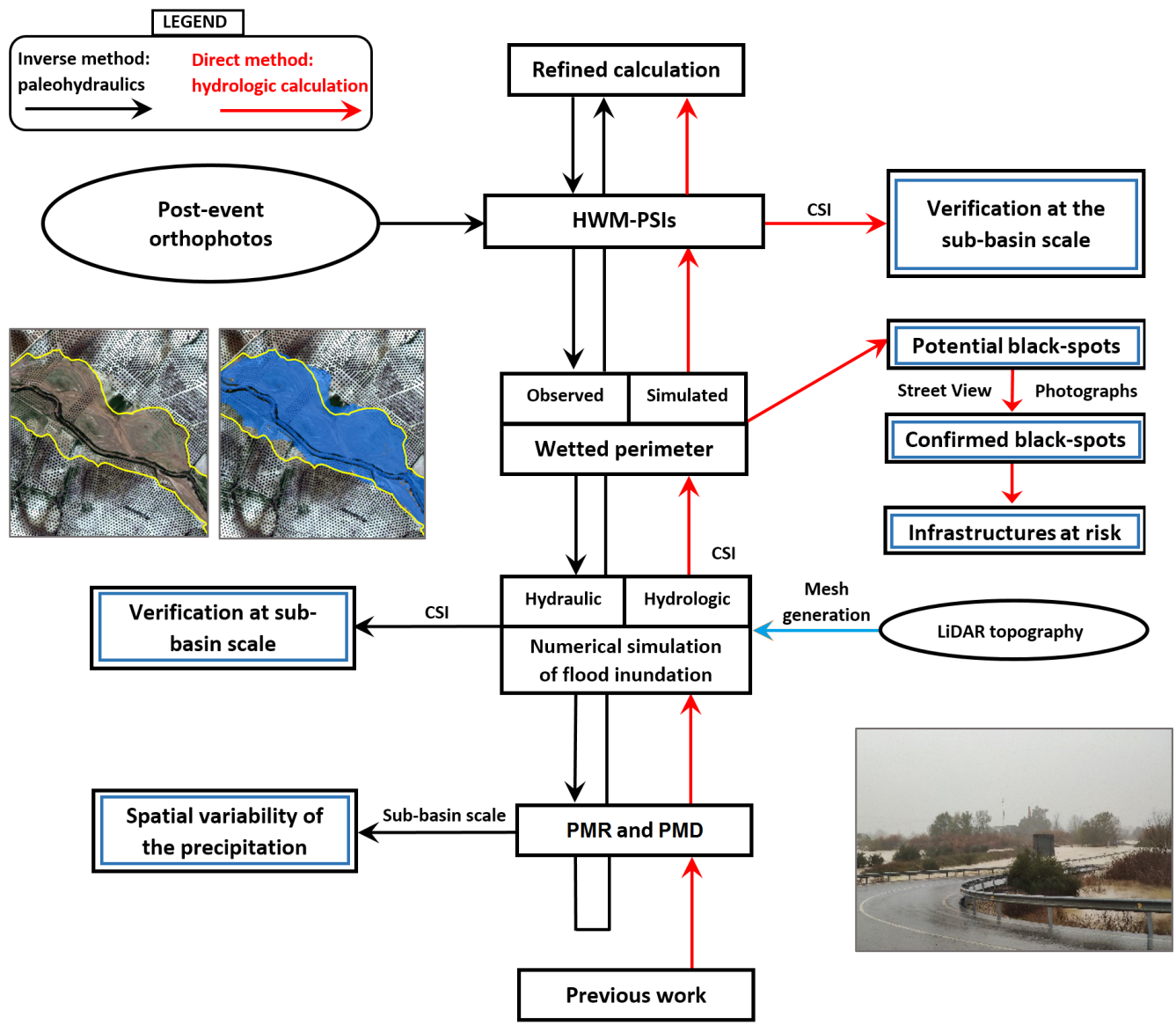

Figure 4. The flowchart summarises the inverse method (black arrows) and the direct approach (red arrows). Blue colour indicates a step common in both procedures.

In the ungauged BII, remote-sensed flood sediments can be traced in the historical orthophotography registry provided accurate information of the observed wetted area in the river reach SA13 (see first row in Figure 5). The optimal value of the discharge that maximised the agreement between the simulated $\left(A_{\bmod }\right)$ and observed $\left(A_{\text {obs }}\right)$ inundation area, referred to as Probable Maximum Discharge (PMD), was PMD $=460 \mathrm{~m}^{3} \cdot \mathrm{s}^{-1}$ [1] Then, the spatial-averaged intensity of the precipitation that provoked the flood was obtained from the drainage area of the upstream basin, $A_{\text {drain }}$, and the inferred PMD under the condition of saturation of surface soils observed in the reconstructed floods, i.e., $\mathrm{PMR}=\mathrm{PMD} / A_{\text {drain }}$. It yield PMR $=5.4 \mathrm{~mm} \cdot \mathrm{h}^{-1}$. In BI we proceeded similarly at the river stretch SP13, that yield the peak-water discharge $\mathrm{PMR}=533 \mathrm{~m}^{3} \cdot \mathrm{s}^{-1}$ and the rainfall intensity PMR $=2.9 \mathrm{~mm} \cdot \mathrm{h}^{-1}$.

We configured the hydrological module of IBERPLUS to solve for the two-dimensional inviscid shallow-water equations, better known as Saint-Venant equations, given by

$$
\begin{aligned}
\frac{\partial h}{\partial t}+\nabla \cdot(h \boldsymbol{u}) & =\text { PMR } \\
\frac{\partial h \boldsymbol{u}}{\partial \hat{t}}+\nabla \cdot(h \boldsymbol{u} \boldsymbol{u})+\nabla\left(\frac{g h^{2}}{2}\right) & =-g h \nabla z-\frac{g h^{2}}{h^{1 / 3}} \boldsymbol{u}|\boldsymbol{u}| .
\end{aligned}
$$

where $t$ is the time, $h$ is the depth of the water measured along the vertical coordinate, $u$ is the depth-averaged velocity vector, $z$ is the bed altitude, and $g$ is the acceleration due to gravity. The source term in the continuity Equation (1) represents the rainfall intensity. Infiltration was neglected because of the soil water repellence in the study site. In the momentum balance equation, the source terms are the bed slope $\nabla z$ and 
the bottom shear stress evaluated with the Manning's roughness coefficient, $n$. We set $n=0.025 \mathrm{~s} \cdot \mathrm{m}^{-1 / 3}$ corresponding to silt and clay. Taking into account that (1) and (2) are the preferred equations to map flood hazard [7,8,48], flood-prone areas can thus be identified as output products.
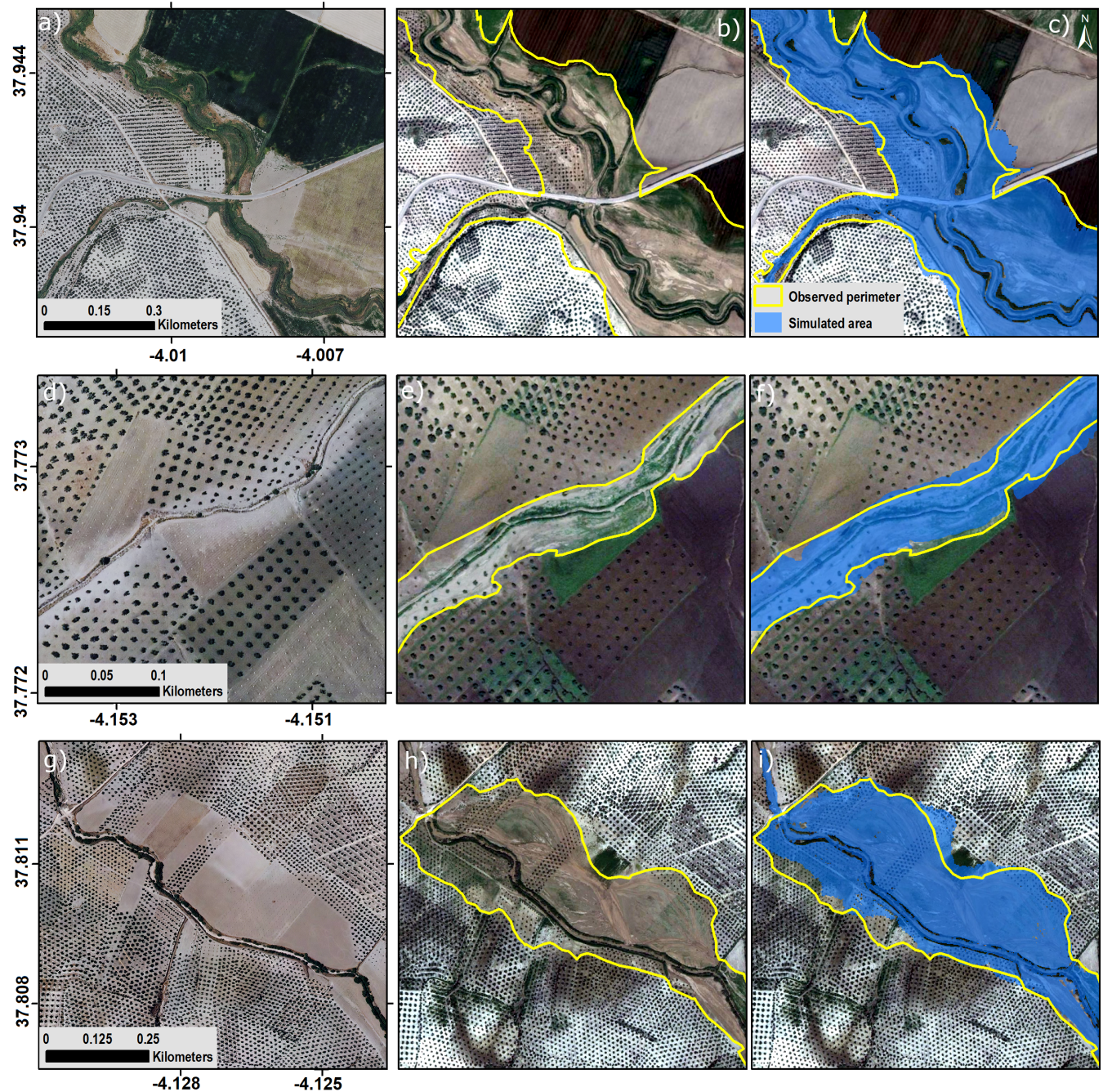

Figure 5. The left column shows three orthoimages in a pre-flood condition of the river stretches denoted as SA13 (first row), SP20 (second row) and SP21 (third row). For the same locations, the column in the middle illustrates slackwater sediments in the post-event orthophotography. The right column shows the comparison between the simulated inundation area (blue colour) and the observed perimeter (yellow line) with an agreement of 90.4, 84.7 and 83.4 percentage, respectively. The comparison of the pre- and post-flood images gives the wetted boundary of the inundation. The original orthophoto (spatial resolution of $0.5 \mathrm{~m} /$ pixel) shows details of the sedimentary deposits not visible at the a4-paper size.

We simulated in the graphics processing unit NVIDIA GeForce GTX 1080 instead of a central processing unit and reduced the computational time by a factor of 10 . To this end, we built a structured computational mesh across the whole study area of $977 \mathrm{~km}^{2}$ with a spatial resolution of $0.5-10 \mathrm{~m}$. The computational grid contains more than 40 million cells. Then, the nodes elevation were obtained from an accurate digital elevation model (DEM) based on Light Detection and Ranging elevations acquired by the Spanish Geographical Institute (https:/ / www.ign.es/ (accessed on 4 November 2020)). The average distance of a point from its neighbours in the LiDAR dataset was $1.41 \mathrm{~m}$, corresponding to the point density of 0.5 points per square meter. The root mean squared error between the 
ground reference and estimated position were $0.3 \mathrm{~m}$ and 0.2 in the horizontal and vertical coordinates, respectively. Previously, the LiDAR data had to be filtered to delete the obstacles (e.g., bridges) that directly affected the flow. In this case, the seasonal behaviour of the river courses allows us to get the actual geometry of the channels in the DEM. The input hyetograph was configured in the IBERPLUS model using the reconstructed PMR values until a time calculation given by $2 \times T=14 \mathrm{~h}$, where $T$ is the estimated concentration time.

The next step was post-processing and verification of the hydrological calculation at the sub-basin scale. Simulated water depths allowed the extraction of the flood mask in the study area, denoted by $A_{\text {mod }}$. In this work, we got a total of 34 inundation areas (see Figure 3b): 18 upstream of SP13 in BI and 16 upstream of SA13 in BII. In these locations, we then undertook a detailed analysis of the remote-sense paleoflood stage following the same approach as Moral-Erencia et al. [1]. Thus, the extension of the observed flooded areas $\left(A_{\text {obs }}\right)$ could be delimited with precision. We then evaluate the critical success index [33],

$$
\mathrm{CSI}=\frac{A_{\mathrm{obs}} \cap A_{\mathrm{mod}}}{A_{\mathrm{obs}} \cup A_{\mathrm{mod}}} .
$$

The analysis of the ensuing values of CSI in the 34 flooded areas, see Figure 6, serves to discuss the reliability of the hydrological calculation and the paleohydrological reconstruction method in the horizontal. A CSI value of 1 indicates a perfect overlap between $A_{\text {mod }}$ and $A_{\text {obs. }}$. Conversely, no overlap exists if CSI reaches the zero value. According to previous studies, there are a reduced number of simulations with a CSI $>0.7$ [34].

The simulation of the unsteady hydrological processes also yields the unsteady hydrograph at any point of the basin, referred to as S-curve [44] (e.g., Figure 7). In the simulated hydrograph, the time when the water discharge becomes constant and reaches the value $\mathrm{PMD}=\mathrm{PMR} \times A_{\text {drain }}$ yields the truth value of the time of concentration $T$. For completeness, we applied the kinematic wave or rational method to estimate the minimum duration of the rainfall event $T$ based on the runoff velocity $U_{\text {PMR }}$ [44]:

$$
\mathrm{T}=\frac{L}{U_{\mathrm{PMD}}}, \quad U_{\mathrm{PMD}}=\left(\frac{\mathrm{PMD} \cdot L}{3.6 \cdot 10^{6}}\right)^{\frac{2}{5}} \cdot S_{0}^{\frac{3}{10}} \cdot n^{-\frac{3}{5}},
$$

where $L$ is the characteristic length of the catchment (e.g., $L=A_{\text {drain }}^{1 / 2}$ in a nearly square basin as BI and BII) and $S_{0}$ is the mean slope of the basin. So the goodness of the theoretical value (4) can be assessed by comparison with the simulation. Furthermore, we study the self-similar hydrological response of BI and BII by making non-dimensional variables. The dimensionless S-curve is constructed by making the discharge and the time nondimensional with respect to the characteristics values PMD and T, respectively.

\subsubsection{Recursive Paleohydrological Reconstruction in Multiple Sub-Basins}

To derive the spatially, non-uniform distribution of the precipitation intensity, we divided the total area of $977 \mathrm{~km}^{2}$ into 40 different sub-basins (22 in BI and 18 in BII), as shown in Figure 3b. There are remote-sensed paleoflood evidence at each sub-basin outlet, where we delimited the extension of the inundated area $A_{\text {obs }}$ (e.g., Figure 5). Subsequently, we searched for the optimal probable maximum discharge in the outlet of each sub-basin by applying the inverse method (Figure 4). In such a step, we inferred the water discharge and the precipitation intensity that maximised the overlapped region between the observed $\left(A_{\text {obs }}\right)$ and simulated $\left(A_{\text {mod }}\right)$ inundation area.

At first, the observed area was visually delimited from slackwater sediment deposits over the post-event orthophotos with GIS software, as illustrated in the middle column of Figure 5. We then built a thin mesh of $0.5 \mathrm{~m}$ spatial resolution for each inundated river reaches and found the optimal value of the water discharge. We increased the streamflow monotonously in the interval between half and twice the peak discharge derived from the hydrological calculation with uniform precipitation (Section 2.2.1). We 
simulated 14 streamflow values in each of the 40 river stretches. This fact amounts to a total of 560 two-dimensional numerical simulations and a large amount of work. After the hydraulic simulation, the CSI (3) was evaluated for each simulated discharge, obtaining a single curve for each sub-basin as displayed in Figure 8a. The peak of the CSI curve yields

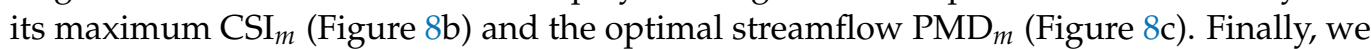
quantified the improvement regarding the uniform precipitation results by comparing the discharges and the critical success index (Figures 8d and 9, respectively).
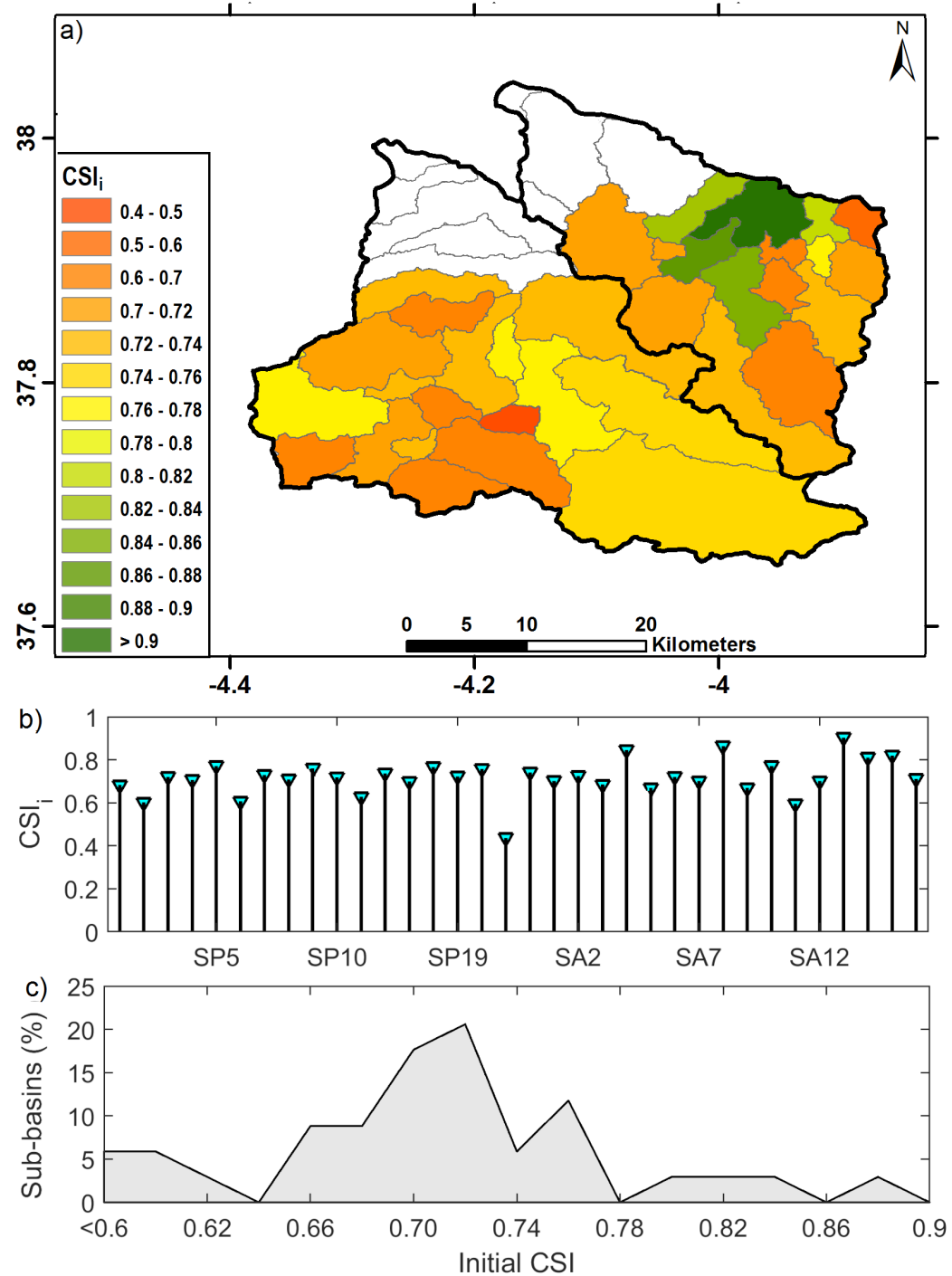

Figure 6. (a) Map of $\mathrm{CSI}_{i}$ calculated with the distributed hydrological model using spatially-uniform precipitation. (b) $\mathrm{CSI}_{i}$ value in each sub-basin. (c) Histogram of $\mathrm{CSI}_{i}(\%)$ in a range between 0.6 and 0.9. The numerous sub-basins with $\mathrm{CSI}_{i} \geq 0.7(0.8)$ indicate a good (excellent) agreement of the predicted flooded areas from hydrological simulation and the reality.

In addition, we characterised the spatial variability of the probable maximum precipitation $\mathrm{PMR}_{m}$ (Figure 10). The reconstruction of $\mathrm{PMR}_{m}$ started in the header of BI and BII. The hydrological processes in the upper sub-basins (e.g., SP22) are independent of the downstream part of the catchment and, thus, the precipitation intensity is readily evaluated with the optimal peak discharge $\left(\mathrm{PMD}_{m}\right)$ and the drainage area of a sub-basin $\left(A_{\text {drain }}\right)$ through the mass balance equation,

$$
\mathrm{PMR}_{m}=\frac{\mathrm{PMD}_{m}}{A_{\text {drain }}}
$$


For dependent sub-basins located downstream (e.g., SP4), the conservation mass processes need to account for the upstream drainage area. Indeed, there is an input streamflow from the neighbouring sub-basins, denoted by $\sum_{n} \mathrm{PMD}_{m}^{n}$. So, the probable maximum rainfall of such sub-basins, which are not at the head, are given by:

$$
\mathrm{PMR}_{m}=\frac{\mathrm{PMD}_{m}-\sum_{n} \mathrm{PMD}_{m}^{n}}{A_{s}}
$$

where $A_{s}$ is the area of the dependent sub-basin.
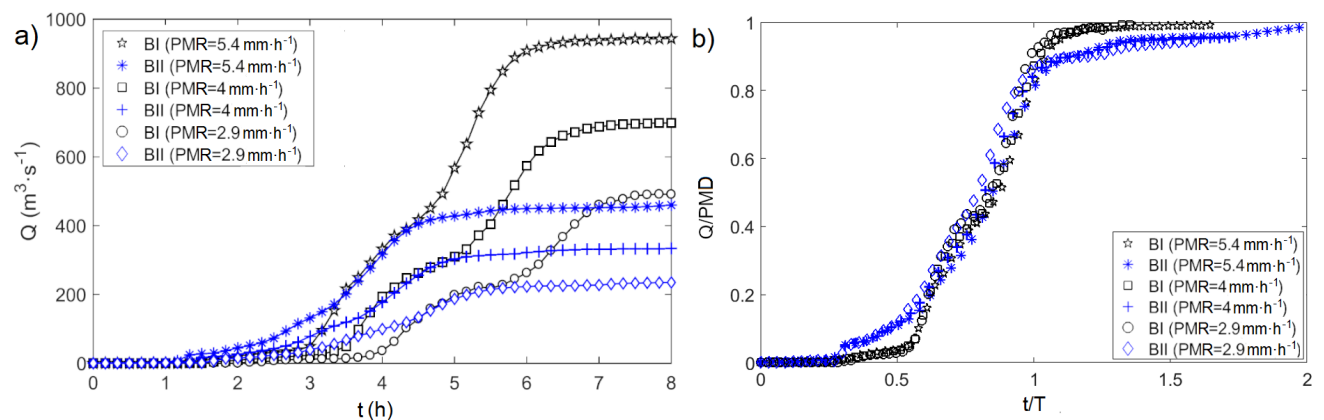

Figure 7. (a) Dimensional hydrographs computed at the outlet of BI and BII with the distributed hydrological model for several values of PMR $\left(\mathrm{mm} \cdot \mathrm{h}^{-1}\right)$. (b) Non-dimensional hydrographs obtained making $Q$ and $t$ dimensionless with respect the characteristic discharge PMD $=\mathrm{PMR} \times A_{\mathrm{drain}}$ and the time of concentration $\mathrm{T}(4)$.

\subsubsection{Verification of the Simulated Water Level and Rainfall Databases}

To benchmark the precision of the new approach explained above (Section 2.2.2), we compared the elevations of the simulated water surface with two sets of data: (i) the shoreline elevation of the inundated areas; (ii) the height of structural high-water marks and slackwater sediments found on roads.

First, we run an additional hydrological simulation with IBERPLUS setting the nonuniform rainfall intensity distribution $\mathrm{PMR}_{m}$ as input hyetograph. We used the same topography and computational domain of Section 2.2.1. The simulation yielded the elevation $\eta=h+z$ of all the flooded areas in BI and BII, where $h$ is the flow depth and $z$ the bed elevation. Subsequently, in the forty boxed areas shown in Figure 3, we obtained the real elevations of the inundated shorelines using a precise digital terrain model based on LiDAR flight with $1.4 \mathrm{~m}$ spatial resolution and $0.2 \mathrm{~m}$ z-coordinate RMS error. Recall that the shorelines were visible in the remote-sensed slackwater sediments (yellow lines in Figure 5). Next, we evaluated the Index of Agreement (IA), Root Mean Square Error (RMSE), Mean Absolute Percentage of Error (MAPE), Bias Index (BIAS) and Scatter Index (SI) of $\eta$ (see details in Barzkar et al. [50]):

$$
\begin{gathered}
I A_{\eta}=1-\frac{\sum_{n=1}^{N}\left(\eta_{\text {mod }}^{n}-\eta_{o b s}^{n}\right)^{2}}{\sum_{n=1}^{N}\left(\left|\eta_{\text {mod }}^{n}-\bar{\eta}_{\text {mod }}\right|+\left|\eta_{o b s}^{n}-\bar{\eta}_{o b s}\right|\right)^{2}} \\
R M S E_{\eta}=\left[\frac{1}{N} \sum_{n=1}^{N}\left(\eta_{\text {mod }}^{n}-\eta_{o b s}^{n}\right)^{2}\right]^{\frac{1}{2}} \\
M A P E_{\eta}=\frac{1}{N} \sum_{n=1}^{N}\left|\frac{\eta_{o b s}^{n}-\eta_{m o d}^{n}}{\eta_{o b s}^{n}}\right| \times 100 \\
\operatorname{BIAS}_{\eta}=\frac{1}{N} \sum_{n=1}^{N} \eta_{\text {mod }}^{n}-\eta_{o b s}^{n}
\end{gathered}
$$




$$
S I_{\eta}=\left\{\frac{1}{N} \sum_{n=1}^{N}\left[\left(\eta_{\text {mod }}^{n}-\bar{\eta}_{\text {mod }}\right)-\left(\eta_{\text {obs }}^{n}-\bar{\eta}_{\text {obs }}\right)\right]^{2}\right\}^{\frac{1}{2}},
$$

where $N$ is the number of samples, $\eta_{\text {mod }}^{n}=h_{\text {mod }}^{n}+z^{n}$ and $\eta_{o b s}^{n}$ are the simulated and observed water surface elevations of the $n$-inundated area, respectively, and $\bar{\eta}_{\text {mod }}$ and $\bar{\eta}_{\text {obs }}$ are the corresponding mean values.
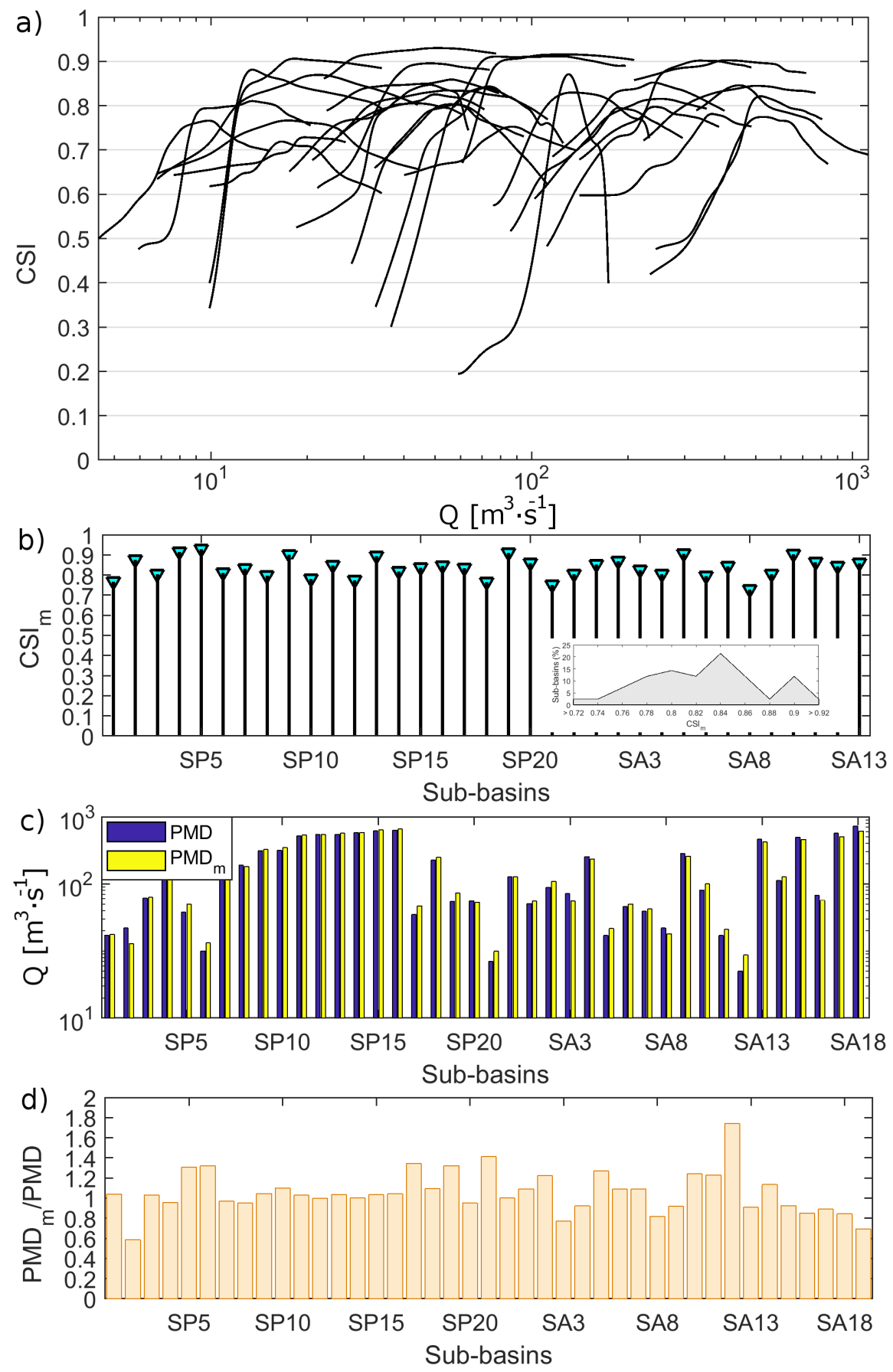

Figure 8. (a) CSI curves as a function of the water discharge $Q$ in the forty-one studied sub-basins computed with the new methodology presented in Section 2.2.2. (b) $\mathrm{CSI}_{m}$ in each sub-basin of BI (SP) and BII (SA). Histogram of $\mathrm{CSI}_{m}$ in inset rectangle. (c) Peak discharges obtained with a spatially-uniform precipitation PMD (magenta) and the recursive paleohydraulic reconstruction $\mathrm{PMD}_{m}$ (yellow). (d) $\mathrm{PMD}_{m}$ to PMD ratio. 


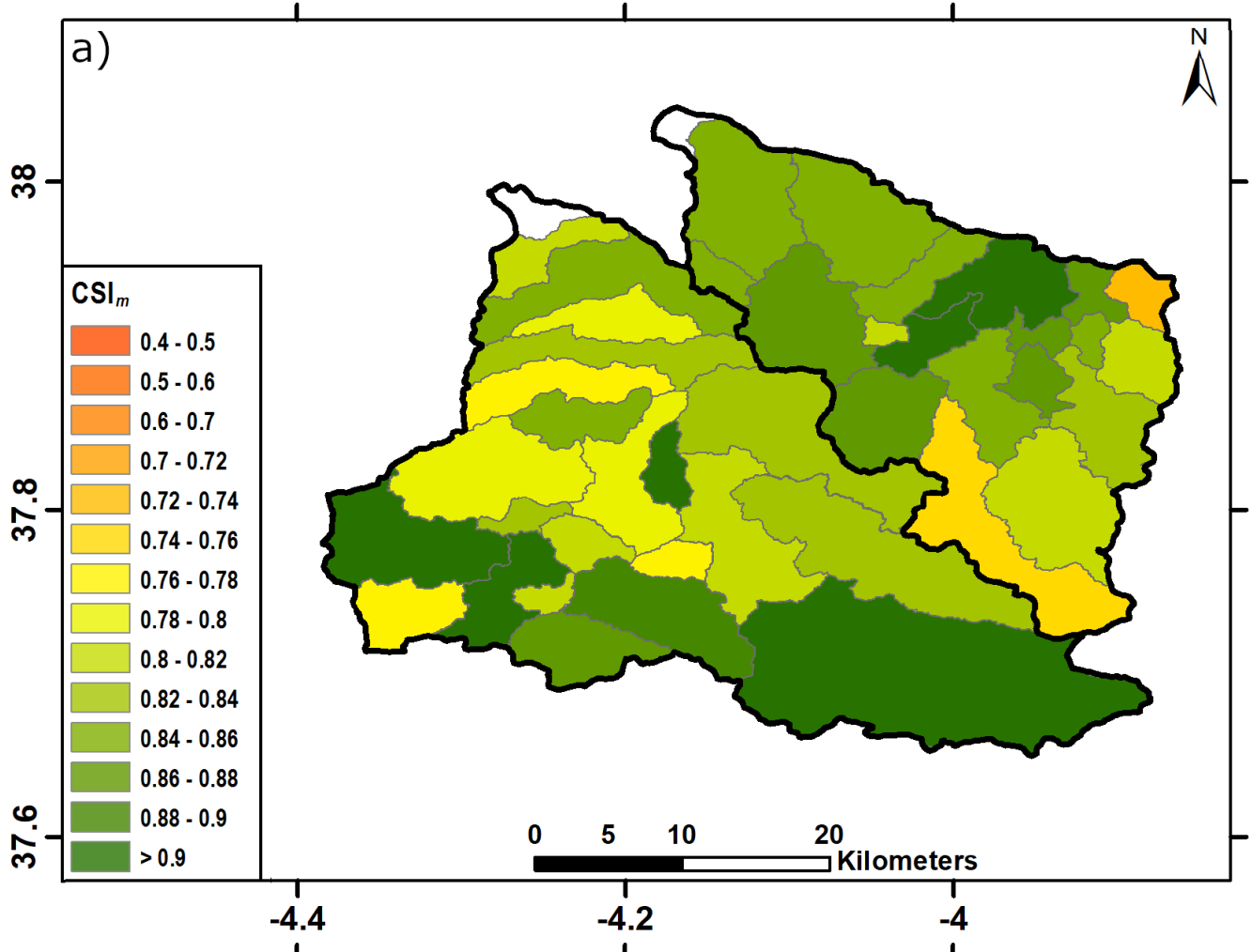

b)

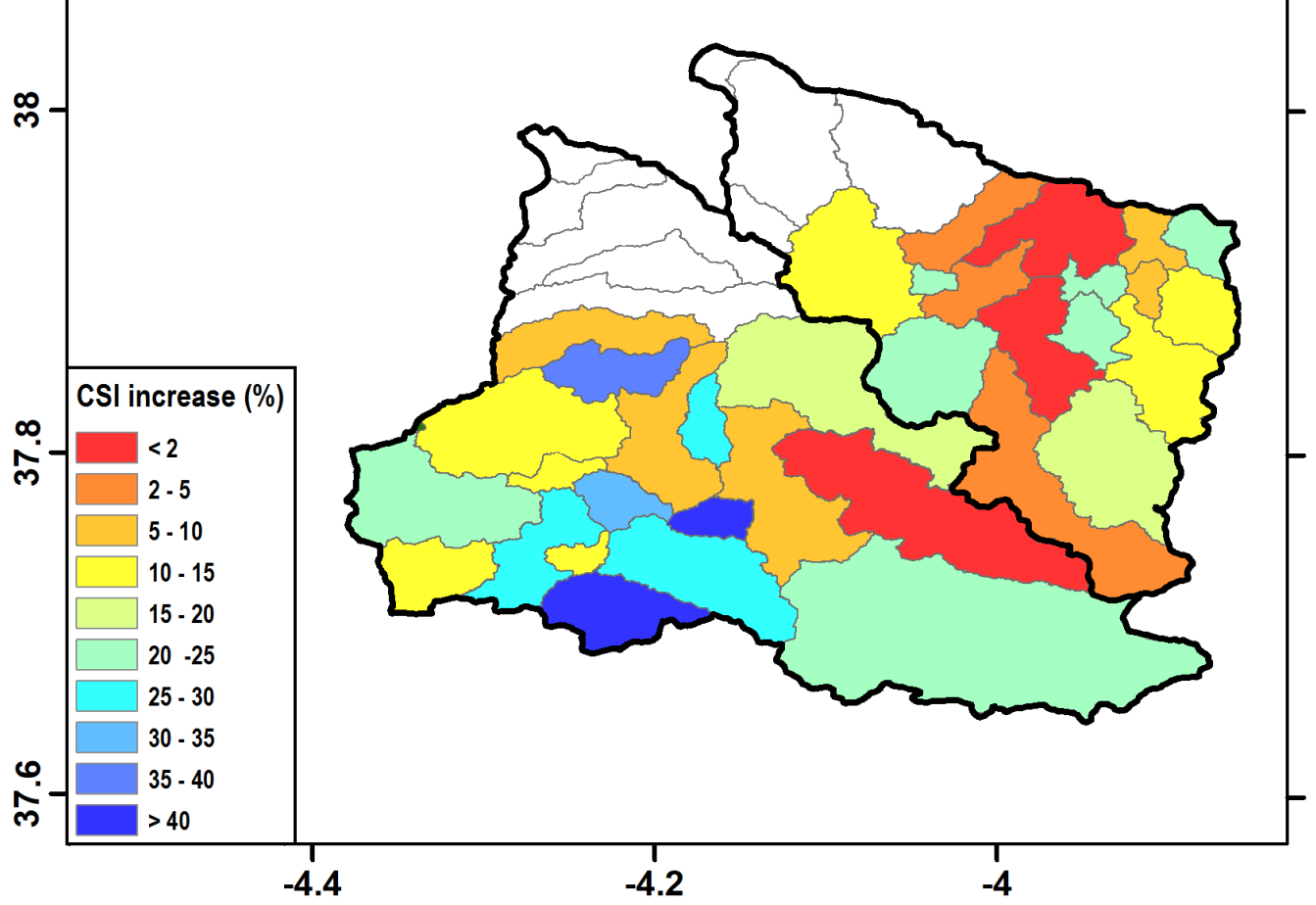

Figure 9. (a) Map of the quality parameter $\mathrm{CSI}_{m}$ after the optimal, recursive paleohydraulic reconstruction. (b) Relative increase of $\mathrm{CSI}_{m}$ with respect to the CSI values shown in Figure 6a.

In addition, we detected structural high-water marks and sedimentary deposits in inundated roads of the transport network using Google Street View, [51], local press and in-situ photographs. The elevations of the flooded roads are also available from the digital terrain model (https://pnoa.ign.es/ (accessed on 4 November 2020)). If the simulated elevation was more significant than the road height, then we denoted the flood hazard 
prediction at this location as 'high confidence'. When they were equal, then we referred to the places as 'good confidence'. Lastly, if the flood evidence was unclear, we assigned 'low confidence'.
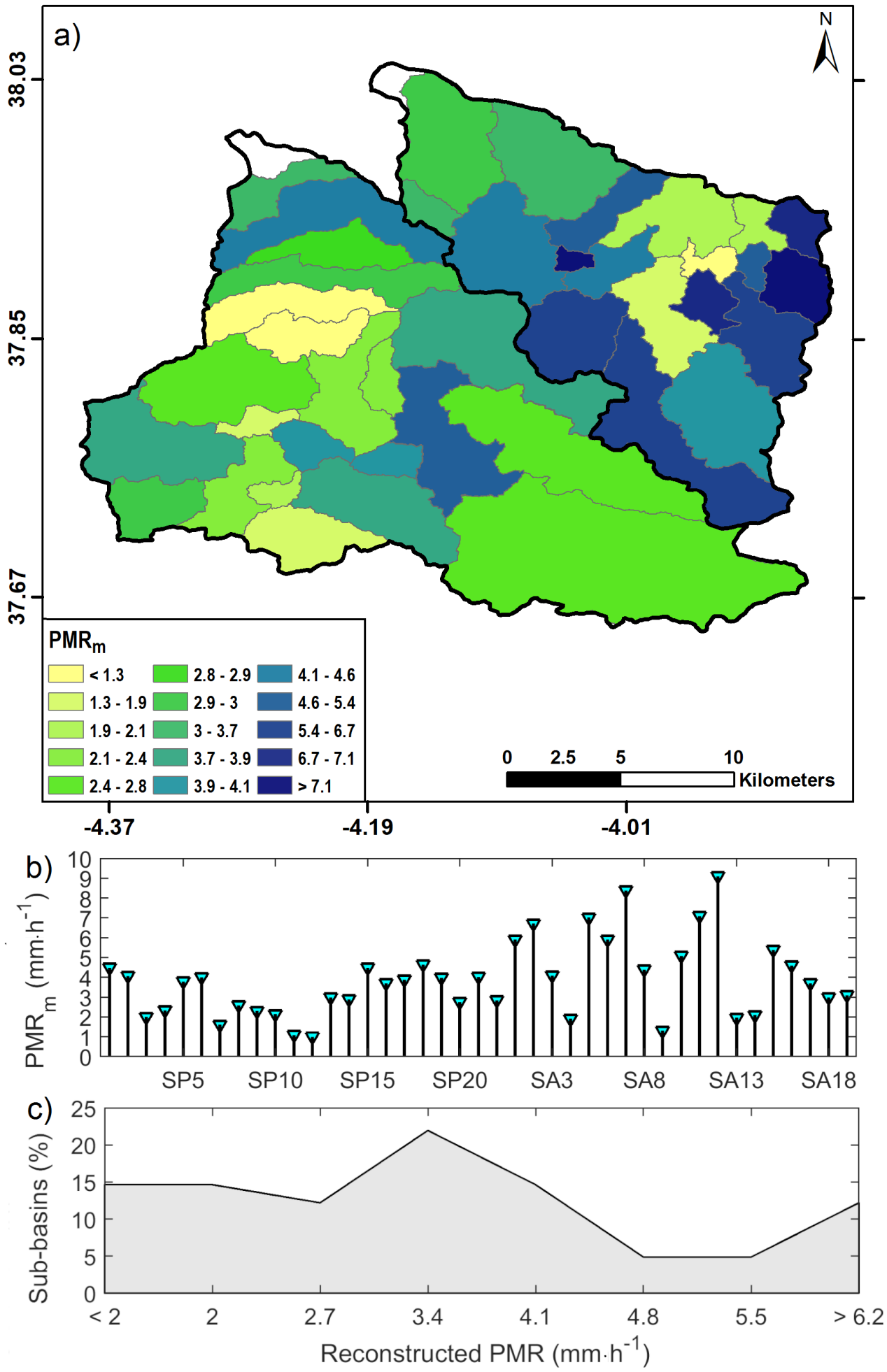

Figure 10. (a) $\mathrm{PMR}_{m}$ map $\left(\mathrm{mm} \cdot \mathrm{h}^{-1}\right)$ obtained with the recursive paleohydrological method, showing the heterogeneous distribution of the precipitation intensity. We also indicated the $500 \mathrm{hPa}(\sim 5500 \mathrm{~m})$ wind direction at the moment of the peak precipitation (03 UTC of 23 December 2009) according to NOAA GDAS reanalysis [52]. (b) $\mathrm{PMR}_{m}$ value in each sub-basin. (c) Histogram of $\mathrm{PMR}_{m}$. 
We discuss the accuracy of the values of the accumulated precipitation from four daily (AEMETv2, Spain02, TMPA, TMPA-RT) and five sub-daily (IMERG-Final, Persian-CCS, Pdir-Now, CMORPH, GSMaP) databases based on rain gauges and satellites. To this end, we compared the database values with respect to the result TPMR provided by our method in BI and BII. TPMR is evaluated by multiplying the mean rainfall intensity $\overline{\mathrm{PMR}}_{m}$ and the real duration of the rainfall $T_{\text {rain }}$ :

$$
\overline{\mathrm{TPMR}}=T_{\text {rain }} \times \overline{\mathrm{PMR}}_{m} .
$$

Because the extreme hydrological event was simultaneous in BI and BII, we set $T_{\text {rain }}=10.5 \mathrm{~h}$ according to the duration of the rising $\operatorname{limb}(7.5 \mathrm{~h})$ and the plateau stage at peak flow $(3 \mathrm{~h})$ of the hydrograph measured in the stream gauging station of BI [1].

\section{Results and Discussion}

We present the results progressively following the same order as the Methods. First, we quantified the accuracy of our previous paleohydrological reconstruction by analysing the spatial distribution of the CSI (Section 3.1.1) and the S-curve at the basin outlet (Section 3.1.2) for a uniform rainfall. Then, we undertook a refined paleohydrological calculation with the main aim of maximising the CSI in multiple sub-basins (Section 3.2.1), allowing us to obtain the spatial distribution of the precipitation (Section 3.2.2). Finally, we evaluated the precision of the recursive calculation in terms of water level (Section 3.3).

\subsection{Quality of the Hydrological Calculation with a Uniform Precipitation}

\subsubsection{Verification of Flooding Maps through the Critical Success Index}

Figure 6a shows the contour map of the CSI (3) (denoted with the sub-index $i$ from now on) after the application of the method explained in Section 2.2.1. The $\mathrm{CSI}_{i}$ corresponds to the 18 sub-basins of BI and the 16 sub-basins of BII upstream of the reaches SP13 and SA13 (Figure 3b), respectively, where the former paleohydrological reconstruction of MoralErencia et al. [1] was done. All these sub-basins occupy the $75 \%$ of the whole area of study. The excluded part of the catchment lies downstream of the stretches SP13 and SA13 (see the white area in Figure 6a).

The average value in the 34 sub-basins was $\overline{\mathrm{CSI}_{i}}=0.73$, nearly the same as the averages of $\mathrm{BI}\left(\overline{\mathrm{CSI}}_{i}^{\mathrm{BI}}=0.72\right)$ and $\mathrm{BII}\left(\overline{\mathrm{CSI}}_{i}^{\mathrm{BII}}=0.75\right)$. Such a values indicate a good agreement, particularly, concerning previous flood simulation studies that rarely achieved $\mathrm{CSI}_{i}>0.7$ [34]. In BI, the maximum and minimum $\mathrm{CSI}_{i}$ was 0.77 in SP5 and 0.44 in SP21, respectively. Geographically, the eastern sub-basins exhibited a greater overlap between the observed and simulated inundated areas, with $\mathrm{CSI}_{i}=0.74$. The extremes in BII were slightly larger than in BI: the maximum was 0.90 in SA13 and the minimum reached 0.59 in SA11 (Figure 6b). The sub-basins with excellent agreement, i.e., $\mathrm{CSI}_{i} \geq 0.8$, are located in the north-east of BII (see areas in green in Figure 6a). The most-frequent values of $\mathrm{CSI}_{i}$ ranges between 0.66 and 0.78 , showing a relative frequency of $8.8 \%(0.66-0.7), 17.7 \%$ (0.7-0.72), 20.6\% (0.72-0.74), 5.9\% (0.74-0.76) and $11.8 \%$ (0.76-0.78), see Figure 6c. We got excellent values of $\mathrm{CSI}_{i}>0.7$ in 26 of the 34 sub-basins analysed. Hence, the use of a spatially-uniform precipitation minimised the intrinsic errors caused by the spatial irregularity of the rainfall, especially in the lower river stretches.

We conclude that the simple paleohydraulic methodology of reconstruction of discharge and precipitation introduced by Moral-Erencia et al. [1], combined with the direct simulation of the rainfall-runoff hydrological processes (Section 2.2.1), serves to characterise flood-prone areas in drainage basins lower than $2000 \mathrm{~km}^{2}$. With the execution of only one calculation of the distributed hydrological model, we could identify newer locations at risk and verify the calculation quality through the CSI parameter. Therefore, the direct method is valuable for predicting the wetted perimeter and flood dynamics of short-rain flood events at the basin scale with a fast mode and notable reliability. 


\subsubsection{Dimensional and SELF-Similar Analysis of the Hydrograph: S-Curve}

Figure 7a depicts the dimensional hydrograph obtained at the outlet of BI (black colour) and BII (blue colour), respectively, setting the intensity of precipitation to PMR $=2.9$ (circles) and $5.4 \mathrm{~mm} \cdot \mathrm{h}^{-1}$ (asterisks) in the hydrological model. Because of its shape, the hydrograph is referred to as S-curve. The delay between the beginning of the precipitation and the peak flow, called time of concentration $(T)$, is the time that elapses from the start of the calculation (in hours) until the water discharge $Q$ achieves a steady-state with $Q=\mathrm{PMD}=\mathrm{PMR} \times A_{\text {drain }}$. The theoretical estimation (4) yield $\mathrm{T}=7.2 \mathrm{~h}$ in BI and $4.7 \mathrm{~h}$ in BII, which are a good approximation because the simulated water discharges at that time were $91 \%$ and $82 \%$ of PMD, respectively.

The water discharge $Q$ and the physical time $t$ were made dimensionless with PMD and $\mathrm{T}(4)$ to construct the dimensionless S-curves (Figure $7 \mathrm{~b}$ ). Interestingly, the dimensionless hydrographs nearly overlap even though both basins slopes and areas differed and the intensity of the rainfall events was also substantially different. Hence, the hydrological response between the two study basins was analogous for the considered rain events, indicating a self-similar behaviour during all flood stages.

We further explored BI and BII self-similarity by running three simulations in each basin for a precipitation event with an intensity of PMR $=2.9,4$ and $5.4 \mathrm{~mm} \cdot \mathrm{h}^{-1}$ and duration of $8 \mathrm{~h}$. In the end, the discharges at the basins outlets reached the steadystate (Figure 7a). The peak discharged were 492,697 and $954 \mathrm{~m}^{3} \cdot \mathrm{s}^{-1}$ in BI and 226, 361 and $453 \mathrm{~m}^{3} \cdot \mathrm{s}^{-1}$ in BII. Such results are in excellent agreement with the rational method, i.e., $\mathrm{PMD}=\mathrm{PMR} \times A_{\mathrm{drain}}$, and indicates that the flow achieved the steady-state in the whole basin at the end of the six numerical simulations. The theoretical time of concentration (4) was $\mathrm{T}=7.2,6.3$ and $5.9 \mathrm{~h}$ in BI and 5.5, 5.1 and $4.7 \mathrm{~h}$ in BII. The decrease in concentration time agrees with the increase in PMR, faster flow velocities, and higher peak flows during the flood. To conclude, the water discharge and the physical time were made dimensionless with PMD and T, as shown in Figure $7 \mathrm{~b}$. In each basin, independently of the value of the rainfall intensity, the hydrographs are self-similar. Indeed, in BI, the three dimensionless S-curves overlap, as well as in BII. This result strengthens the findings described above.

\subsection{Recursive Paleohydrological Reconstruction at the Sub-Basin Scale}

\subsubsection{Peak Discharge Calculation from Optimal Analysis of CSI}

Figure 8a shows the curves CSI versus water discharge $Q$ in the forty-one sub-basins of BI and BII. In general, all the curves exhibit a sharp rising limb that flattens out to reach optimal values (denoted with the sub-index $m$ from now on). The maximum overlap between the simulated and the observed inundated area occurs when CSI achieves its maximum $\mathrm{CSI}_{m}$ at the peak discharge $Q=\mathrm{PMD}_{m}$ corresponding to the most probable discharge. For larger water discharges, i.e., $Q>\mathrm{PMD}_{m}$, the falling limb of the curves shows a smoother slope than the rising limb. Note that the simulated discharges varied in the wide range of 10 to $10^{3} \mathrm{~m}^{3} \cdot \mathrm{s}^{-1}$. The great variability of the water discharge indicates the multiple sizes of the floodplains and geomorphologies of the corresponding river stretches.

Next, the inferred peak discharges $\mathrm{PMD}_{m}$ from the refined paleohydraulic method are shown with yellow bars in Figure 8c. For the sake of comparison with our previous work [1], the water discharges PMD corresponding with the uniform precipitation PMR = $2.9 \mathrm{~mm} \cdot \mathrm{h}^{-1}$ in BI and $5.4 \mathrm{~mm} \cdot \mathrm{h}^{-1}$ in BII are also depicted in purple bars. Overall, both series of water discharges are similar. To establish a quantitative comparison, we now introduce the parameter $\lambda$ defined as the ratio of both peak discharges $\lambda \equiv \mathrm{PMD}_{m} / \mathrm{PMD}$, see Figure $8 \mathrm{~d}$. The mean value and the standard deviation of $\lambda$ in the forty-one basins were $\bar{\lambda}=1.05$ and $\sigma_{\lambda}=0.21$, respectively. Similar statistics were obtained in BI and BII with: $\bar{\lambda}^{\mathrm{BI}}=1.07, \bar{\lambda}^{\mathrm{BII}}=1.03, \sigma_{\lambda}^{\mathrm{BI}}=0.18$ and $\sigma_{\lambda}^{\mathrm{BI}}=0.24$. Hence, on average, the estimated peak discharge can be improved up to $\sim 20 \%$ thanks to the recursive method. The largest improvements were found in SP2 and SA12 because the simpler method of Moral-Erencia 
et al. [1] under- and over-predicted the water discharge by $80 \%$ and $40 \%$, respectively, concerning the recursive method (Section 2.2.2).

To evaluate the horizontal accuracy of the recursive method in terms of the prediction of the inundation areas, we describe now the $\operatorname{CSI}_{m}$ map in Figure 9a. Furthermore, Figure $9 \mathrm{~b}$ establishes the relative differences of $\mathrm{CSI}_{m}$ concerning the previous $\mathrm{CSI}_{i}$ calculation from Section 3.1.1. Both figures clearly illustrate that the refined method was even more accurate than the former one that assumed a spatially-uniform precipitation. Indeed, $\mathrm{CSI}_{m}$ (Figure 9a) is always higher than $\mathrm{CSI}_{i}$ (Figure 6a). The average values in BI and BII were $\overline{\mathrm{CSI}}_{m}^{\mathrm{BI}}=0.85$ and $\overline{\mathrm{CSI}}_{m}^{\mathrm{BII}}=0.84$, respectively. They are $18.4 \%(\mathrm{BI})$ and $12.1 \%$ (BII) larger than the former values $\overline{\mathrm{CSI}}^{\mathrm{BI}}=0.72$ and $\overline{\mathrm{CSI}}^{\mathrm{BII}}=0.75$. The maximum and minimum of $\mathrm{CSI}_{m}$ were as high as 0.93 (SP5) and 0.77 (SP21) in BI, and 0.91 (SA8) and 0.73 (SA11) in BII. The paleohydraulic reconstruction was excellent in six sub-basins with $\mathrm{CSI}_{m}>0.9$, and very good in thirty-four sub-basins with $\mathrm{CSI}_{m}>0.8$. The agreement between the simulated and the observed flooded area was therefore excellent in most of the river stretches. The most frequent values of $\mathrm{CSI}_{m}$ were found in the ranges of $0.78-0.86$ and $0.9-0.92$ as depicted the rectangle in Figure $8 b$, showing a relative frequency of $7.5 \%$ $(0.76-0.78,0.82-0.84,0.86-0.88$ and $0.9-0.92), 10 \%(0.8-0.82)$ and $22.5 \%(0.84-0.86)$.

Geographically, the upper stretch of BI and the middle of BII concentrated the highest values $\mathrm{CSI}_{m} \geq 0.86$. The lowest values developed in the intermediate region of $\mathrm{BI}$ while, in BII, they occurred in the two sub-basins SA2 $\left(\mathrm{CSI}_{m} \geq 0.72\right)$ and SA11 $\left(\mathrm{CSI}_{m} \geq 0.78\right)$ as shown in Figure 9a. The refined paleohydraulic calculation also incremented the overlap between the observed and simulated areas more than $20 \%$ in thirty sub-basins (Figure $9 \mathrm{~b}$ ) regarding the earlier calculation (Figure 6a). The maximum improvement occurred in SP2, where CSI increased from 0.6 to 0.88 (relative difference of $45 \%$ ).

\subsubsection{Spatial Distribution of the Precipitation}

We calculated the probable maximum rainfall $\mathrm{PMR}_{m}$ in each sub-basin using the reconstructed streamflow $\mathrm{PMD}_{m}$ and the mass balance Equations (5)-(6). Results are summarised in Figure 10.

Geographically, the spatial resolution of the precipitation map in Figure 10a was $25.3 \mathrm{~km}^{2}$ (BII) and $30.7 \mathrm{~km}^{2}$ (BI). Such high-resolutions allowed us to quantify the nonuniform spatial distribution of the precipitation rate during the short-rain event. We found abrupt variations of $\mathrm{PMR}_{m}$ larger than $100 \%$ between sub-basins located closer than $5 \mathrm{~km}$. In BII, the highest values developed in the south and south-east of the basin with $5.4 \leq \mathrm{PMR}_{m} \leq 9.1 \mathrm{~mm} \cdot \mathrm{h}^{-1}$. The lowest rainfall fell in the basin central strip, with $\mathrm{PMR}_{m} \leq 2.5 \mathrm{~mm} \cdot \mathrm{h}^{-1}$. In BI, the highest values occurred in the middle of the basin $\mathrm{PMR}_{m}>3.7 \mathrm{~mm} \cdot \mathrm{h}^{-1}$. The lowest values happened in two sub-basins in the north-west region with $\mathrm{PMR}_{m} \leq 1.3 \mathrm{~mm} \cdot \mathrm{h}^{-1}$. Interestingly, Figure 10a shows a continuous WSW-ENE alignment of the highest values of the precipitation rates, which may be produced for a local storm moving in such area. This argument is compatible with the reanalysis data of the Global Data Assimilation System (GDAS) of NOAA Air Resources Laboratory [52] for the moment of observed peak precipitation (03 UTC of 26 December 2009). The dominant wind at $500 \mathrm{hPa}(\sim 5500 \mathrm{~m})$ in the south of Spain was $240-250^{\circ}$ (WSW to ENE) with a marked-up maritime trajectory from the Atlantic Ocean. Hence, the synoptic displacement is compatible with the formation of local storms and the observed alignment of the highest precipitation rates.

To draw an overall picture of the rainfall rate, we considered two statistical parameters, i.e., the spatial average $\overline{\mathrm{PMR}}_{m}$ and the weighted standard deviation $\sigma_{\mathrm{PMR}_{m}}$ given by

$$
\overline{\mathrm{PMR}}_{m}=\sum_{i=1}^{N} w_{i} \mathrm{PMR}_{m, i},
$$




$$
\sigma_{\mathrm{PMR}_{m}}=\left[\sum_{i=1}^{N} w_{i}\left(\mathrm{PMR}_{m, i}-\overline{\mathrm{PMR}}_{m}\right)^{2}\right]^{\frac{1}{2}} .
$$

The weight coefficient $w_{i}$ in (13) and (14) was defined as the ratio of the sub-basin area $A_{i}$ with respect to the basin extent,

$$
w_{i}=\frac{A_{i}}{\sum_{i=1}^{N} A_{i}} .
$$

The number of sub-basins in BI were $N=22$ with $0.68 \% \leq w_{i} \leq 20 \%$ and, in BII, we got $N=19$ with $0.7 \% \leq w_{i} \leq 12 \%$. The wide ranges of the weight values highlight the importance of accounting for the sub-basins areas in the weighted statistical variables $\overline{\mathrm{PMR}}_{m}(13)$ and $\sigma_{\mathrm{PMR}_{m}}(14)$.

Evaluating (13) yields $\overline{\mathrm{PMR}}_{m}^{B I}=3.07$ and $\overline{\mathrm{PMR}}_{m}^{B I I}=4.59 \mathrm{~mm} \cdot \mathrm{h}^{-1}$. The mean rainfall rates derived with the new method in both basins were close to the former ones, i.e., 2.9 in $\mathrm{BI}$ and $5.4 \mathrm{~mm} \cdot \mathrm{h}^{-1}$ in BII [1]. Hence, the relative errors in our former calculations were $5.6 \%$ (BI) and $17.6 \%$ (BII). Obviously, the new approach proposed in this work (Section 2.2.2) is more accurate than the former one because it accounts for the spatial variability of the precipitation. As a matter of fact, the novel approach yields not only the mean value (13) but also the standard deviation (14). We got $\sigma_{\mathrm{PMR}_{m}}^{B I}=0.92$ and $\sigma_{\mathrm{PMR}_{m}}^{B I I}=1.83 \mathrm{~mm} \cdot \mathrm{h}^{-1}$. Hence, the coefficient of variation $\mathrm{CV}=\overline{\mathrm{PMR}}_{m} / \sigma_{\mathrm{PMR}_{m}}$ was $30 \%$ and $40 \%$ in BI and BII, respectively.

Finally, Figure $10 b, c$ depict the particular values of each sub-basins as well as the ensuing histogram. The maximum and minimum values in BI were 1 (SP18) and $4.65 \mathrm{~mm} \cdot \mathrm{h}^{-1}$ (SP12). In BII, such values were 1.3 (SA9) and $9.14 \mathrm{~mm} \cdot \mathrm{h}^{-1}$ (SA12). The most frequent ranges were $3.4-4.1 \mathrm{~mm} \cdot \mathrm{h}^{-1}$ with a relative frequency of $22.5 \%$ (9 of 40 sub-basins). The remaining data was distributed in the following intervals: $\mathrm{PMR}_{m}<2(15 \%, 6$ sub-basins), $2 \leq \mathrm{PMR}_{m}<2.7$ (15\%, 6 sub-basins), $2.7 \leq \mathrm{PMR}_{m}<3.4(12.5 \%, 5$ subbasins), $3.4 \leq \mathrm{PMR}_{m}<4.1$ (15\%, 6 sub-basins), $4.1 \leq \mathrm{PMR}_{m}<4.8$ (5\%, 2 sub-basins), $4.8 \leq \mathrm{PMR}_{m}<6.2$ (5\%, 2 sub-basins) and $\mathrm{PMR}_{m} \geq 6.2$ (12.5\%, 5 sub-basins). Taking into account that such a histogram does not correspond with a common statistical distribution, and that the spatial variability of the precipitation is somehow aleatory, we conclude that the downscaling approach presented in this work is necessary to quantify with accuracy the hydrological variables at the sub-basin scale.

\subsection{Verification of the Simulated Water Level and Rainfall Databases}

We conclude by evaluating the accuracy of the flood hazard maps by comparing the simulated water levels using the non-uniform precipitation distribution $\mathrm{PMR}_{m}$ with the observed flood levels, as explained in Section 2.2.3.

The first set of data represents the elevations of the shorelines, as shown in Figure 11. The black straight line depicts the perfect agreement between the simulation and reality. The square symbols indicate the simulated water elevations. The accuracy of the proposed method is excellent because the square symbols overlap the solid line. Quantitatively, evaluating the statistical measures (7)-(11), we got $I A_{\eta}=0.99, R M S E_{\eta}=0.16 \mathrm{~m}$, $M A P E_{\eta}=0.05, B I A S_{\eta}=0.015 \mathrm{~m}$ and $S I_{\eta}=0.16 \mathrm{~m}$. Such results confirm the good performance of our method concerning the observed water elevations. IA nearly achieves the optimal value of one, indicating a perfect agreement between the observed and simulated water elevations. $R M S E_{\eta}=0.16 \mathrm{~m}$ represents a small deviation of the simulated water level and, also, regarding the mean flow depth of $\bar{h}_{\text {mod }}=3.5 \mathrm{~m}$. The average absolute percentage of error, given by $M A P E_{\eta}$, is close to the zero value. However, such parameter is not really useful because the elevations and steep slopes of the study site ensures $\left|\eta_{o b s}^{n}-\eta_{m o d}^{n}\right|=\left|h_{o b s}^{n}-h_{m o d}^{n}\right| \ll \eta_{o b s}^{n}$, leading to MAPE $\rightarrow 0$. BIAS $\eta_{\eta}$ is also around zero, indicating a negligible over-prediction of the simulated water elevations. Finally, $S I_{\eta}=0.16 \mathrm{~m}$ indicates that the percentage of RMS difference with respect to the mean of $\eta_{\text {obs }}$ is also small. 
The second set of data are flood evidence in the roads found using Google Street View [51], local press news and in-situ photographs. The dots in Figure 12 show the locations of the 79 structural high-water marks and sedimentological deposits. According to the criterion given in Section 2.2.3, we assigned the high degree of confidence to 57 of them $(72.2 \%)$, good confidence to $17(21.5 \%)$ and low reliability to $5(6.3 \%)$. To illustrate the realism of our flood hazard analysis, Figure 12 includes some photographs showing postevent flood evidence in six of the points at risk predicted by the simulation. Pictures 1, 2 and 6 show the inundation of the transport network at the expected locations during recent flood events in March 2018 (picture 1) and December 2019 (images 2 and 6). In addition, we included some examples of sedimentological (pictures 4 and 5) and structural high-water records (image 3).

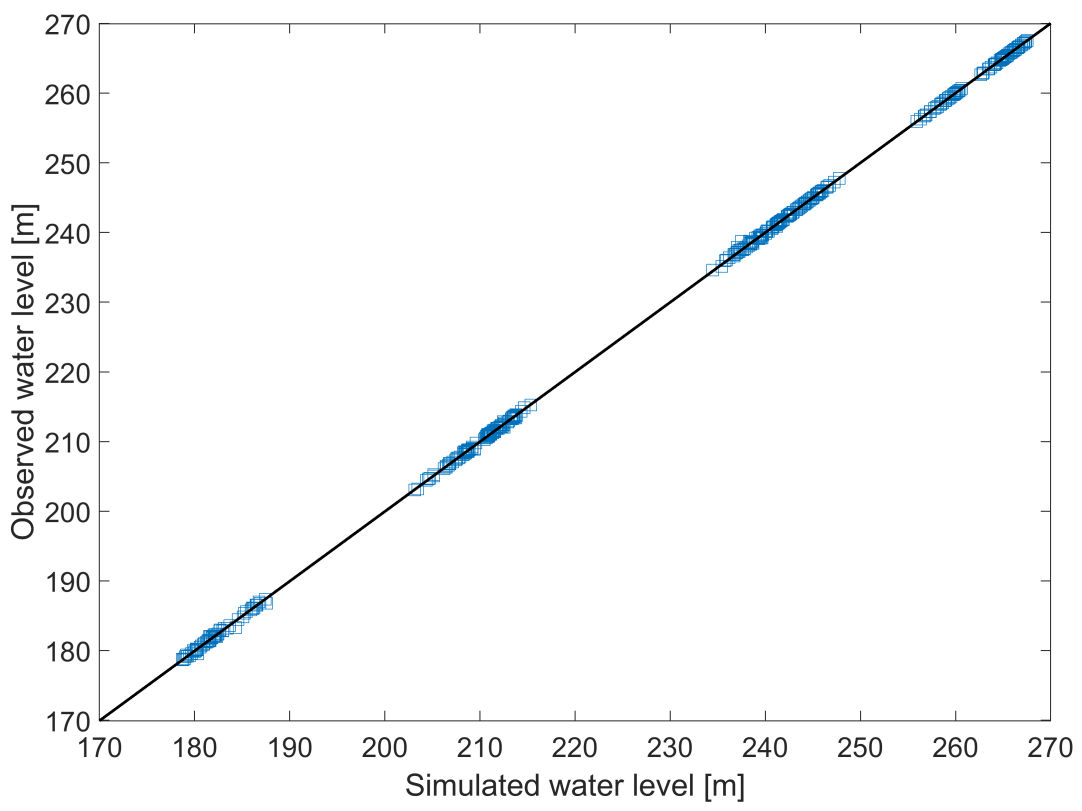

Figure 11. Squares show observed versus simulated water levels in the lower stretches of BII. The straight line depicts the perfect alignment (unit slope).

Regarding the values of the accumulated precipitation for the storm that provoked the 26 December 2009 flood, we summarised the existing databases in Table 1. Overall, satellite-based rainfall under-predicts the accumulated precipitation TPMR (12) given by our method in BI $(32.2 \mathrm{~mm})$ and BII $(48.2 \mathrm{~mm})$ by a great extent. The unique database that gave a comparable value was AEMETv2 [16] interpolating the low-density daily rain gauge network shown in Figure 1. The daily satellite databases may underestimate the accumulated rainfall because of the coarse spatial resolution, which is insufficient to draw the non-uniform patterns depicted in Figure 10. In addition, the daily time resolution is inadequate to characterise sub-daily events. According to our previous study [1], the rainfall lasted $10.5 \mathrm{~h}$. Surprisingly, the sub-daily databases failed in the accumulated precipitation. The closest values correspond to IMERG-Final: $22.5 \mathrm{~mm}$ vs. $32.2 \mathrm{~mm}$ in BI, and $23.5 \mathrm{~mm}$ vs. $48.2 \mathrm{~mm}$ in BII. The discrepancy may be due to the interpolation techniques used for generating a time resolution below $3 \mathrm{~h}$. Recall that such databases use the infrared sensors of geostationary satellites to propagate the movement of the rainfall intensity captured by active or passive microwave sensors [24]. Anyway, the spatial resolution of IMERG-Final (approx. $10 \mathrm{~km}$ ) does not allow the measurement of the precipitation distribution at the sub-basin scale. 
Table 1. Comparison of the accumulated precipitation given by our method, $\overline{\text { TPMR }}$ (12), in BI and BII, with respect to existing databases (accessed on 14 November 2021). For completeness, we indicate its temporal and spatial resolution.

\begin{tabular}{|c|c|c|c|c|}
\hline Source & Time res. (h) & Spatial res. $\left({ }^{\circ}\right)$ & BI $(\mathrm{mm})$ & BII (mm) \\
\hline$\overline{\mathrm{TPMR}}(12)$ & $\mathrm{T}=7$ & {$[0.027,0.19]$} & 32.2 & 48.2 \\
\hline AEMETv2 [16] (http:/ / www.aemet.es/es / serviciosclimaticos/cambio_climat/datos_diarios?w=2) & 24 & 0.05 & 44.4 & 45.7 \\
\hline Spain02 [17] (http:/ / www.meteo.unican.es/es/datasets/spain02) & 24 & 0.11 & 9.8 & 9.4 \\
\hline TMPA (https://disc.gsfc.nasa.gov/datasets/TRMM_3B42_Daily_7/summary) & 24 & 0.25 & 11.9 & 6 \\
\hline TMPA-RT (https://disc.gsfc.nasa.gov/datasets/TRMM_3B42RT_Daily_7/summary) & 24 & 0.25 & 3.6 & 0.6 \\
\hline IMERG-Final (https:/ / disc.gsfc.nasa.gov/datasets/GPM_3IMERGDF_06/summary) & 0.5 & 0.1 & 22.5 & 23.5 \\
\hline Persiann-CCS (https://chrsdata.eng.uci.edu/) & 0.5 & 0.04 & 14.7 & 12.9 \\
\hline Pdir-Now (https://chrsdata.eng.uci.edu/) & 1 & 0.04 & 8 & 9.4 \\
\hline CMORPH (https:/ / rda.ucar.edu/datasets/ds502.0/) & 0.5 & 0.07 & 10.5 & 11.3 \\
\hline GSMaP (https:/ / sharaku.eorc.jaxa.jp/GSMaP/) & 1 & 0.1 & 12.7 & 14.5 \\
\hline
\end{tabular}

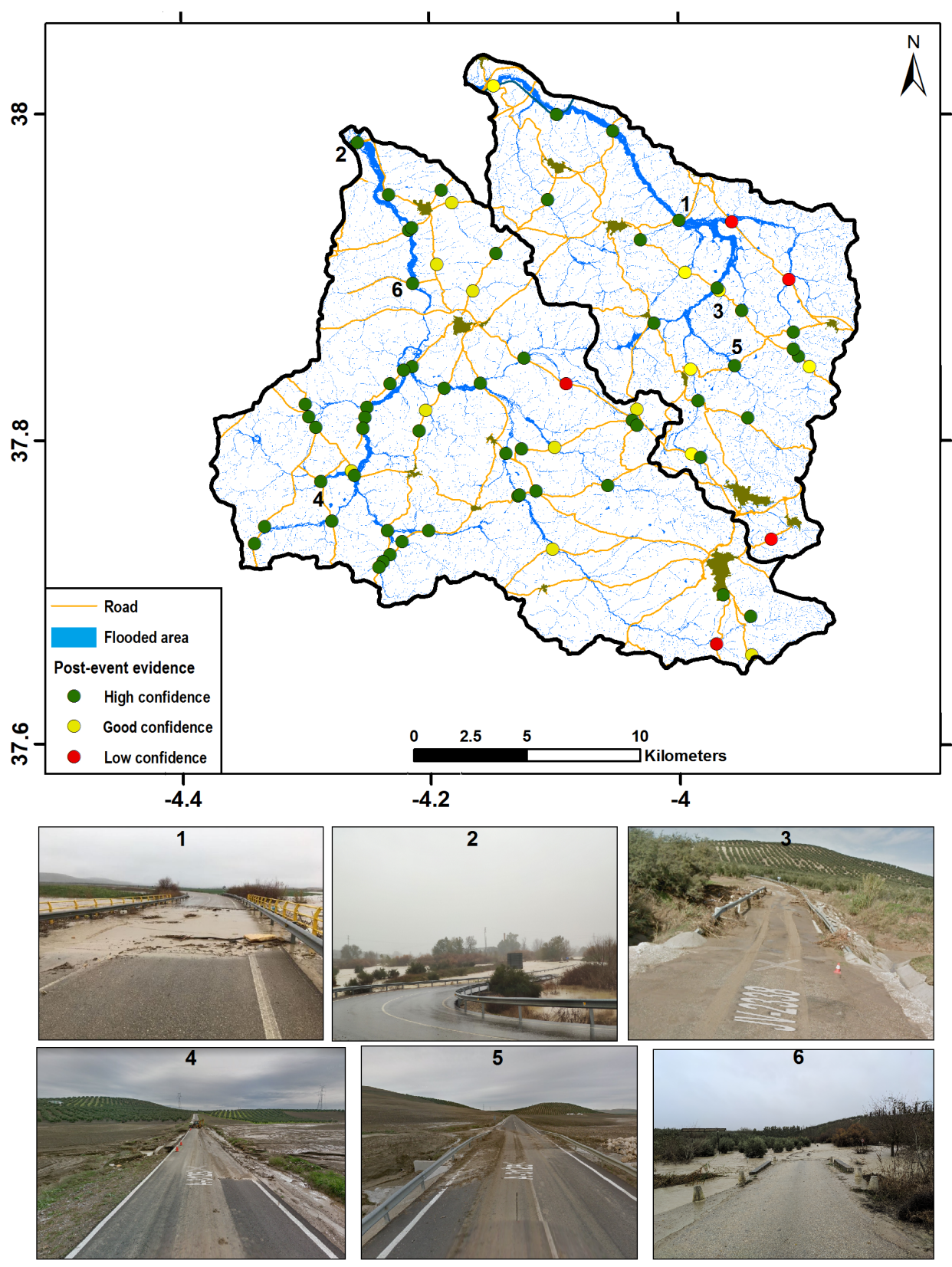

Figure 12. Map of locations at risk of the transport network according to our hydrological simulation. High, good and low confidence is indicated with green, yellow and red circles, respectively, depending on the observation of post-event structural high-water marks and sedimentological records. Pictures 1-6 illustrate examples of flood evidence in different stretches. 


\section{Conclusions}

Because of the increase in frequency and magnitude of short-rain floods in ungauged basins with a drainage area lower than $1000 \mathrm{~km}^{2}$ in southern Spain, we have developed an approach to infer their hydrological characteristics. The outputs are the spatial distribution of the precipitation intensity, the dynamics of surface waters, and flood hazard maps at the local scale. The mean hydrological quantities and other statistical coefficients can also be computed.

Available daily rainfall databases do not describe the precipitation intensity of the studied sub-daily events. In addition, their spatial resolution is too coarse to draw the nonuniform patterns obtained with the paleohydrological method. The local peak discharges inferred in the inundated river stretches recorded the heterogeneity of the extreme rainfall event. The peak discharges were higher than predicted from existing databases in most subbasins, which explains the inundation of more than fifty transport network infrastructures in recent years. Paleohydrology is a powerful instrument that needs to be incorporated in the Spanish Directive FOM/298/2016 to construct safe drainage systems in civil works. It compensates for the low density and irregular geographical distribution of rain/streamflow gauges, making it impossible to extract continuous data around a drainage basin.

We found that incorporating the outputs of the paleohydrological study into the distributed hydrological model IBERPLUS served to map the flood-prone areas and verify the vertical and horizontal accuracy of the paleohydraulic results. The increase in the spatial resolution of the computational grid allowed us to capture the actual basin topography, and the GPUs ran the numerical simulations in a reasonable time. Overall, the agreement between the extent of the simulated and observed flooded areas was excellent concerning previous studies. The simplifications involved in the surface water theory of the kinematic wave equation were also checked and validated with the distributed hydrological model results. The dimensional analysis of the computed hydrographs revealed the self-similarity of the studied basins and rainfall events, which further supports the assumptions of the rational method.

Author Contributions: Conceptualization, all authors; methodology, J.D.d.M.-E. and P.B.; software and modelling, J.D.d.M.-E., P.J.J.-R. and P.B.; validation, all authors; formal analysis, all authors; writing — original draft preparation, J.D.d.M.-E. and P.B.; writing — review and editing, all authors; funding acquisition, P.B. and F.J.P.-L. All authors have read and agreed to the published version of the manuscript.

Funding: This work was funded by "Programa Operativo FEDER 2014-2020" and "Conserjería de Economía y Conocimiento de la Junta de Andalucía" under Grant No. 1380967. J.D.d.M.-E. was supported by the PhD scholarship BES-2016-079117 (MINECO/FSE, UE) from the Spanish National Programme for the Promotion of Talent and its Employability (call 2016).

Institutional Review Board Statement: Not applicable.

Informed Consent Statement: Not applicable.

Data Availability Statement: Data supporting reported results can be found at https://blogs.ujaen. es/prmedina/ (accessed on 14 November 2021).

Conflicts of Interest: The authors declare no conflict of interest.

\section{Abbreviations}

The following abbreviations are used in this manuscript:

BI Basin I (Salado de Porcuna)

BII Basin II (Salado de Arjona)

CPU Central Processing Unit

CSI Critical Success Index

DEM Digital Elevation Model

GPU Graphics Processing Unit

GPS Global Positioning System 


$\begin{array}{ll}\text { HWM } & \text { High-Water Marks } \\ \text { LiDAR } & \text { Light Detection and Ranging } \\ \text { PMD } & \text { Probable Maximum Discharge } \\ \text { PMR } & \text { Probable Maximum Rainfall } \\ \text { PSI } & \text { Paleo-Stage Indicator } \\ \text { IA } & \text { Index of Agreement } \\ \text { RMSE } & \text { Root Mean Square Error } \\ \text { MAPE } & \text { Mean Absolute Percentage of Error } \\ \text { BIAS } & \text { Bias Index } \\ \text { SI } & \text { Scatter Index }\end{array}$

\section{References}

1. Moral-Erencia, J.; Bohorquez, P.; Jimenez-Ruiz, P.; Pérez-Latorre, F. Slackwater Sediments Record the Increase in Sub-daily Rain Flood due to Climate Change in a European Mediterranean Catchment. Water Resour. Manag. 2020, 34, 4431-4447. [CrossRef]

2. IPCC. Climate Change 2013: The Physical Science Basis. Contribution of Working Group I to the Fifth Assessment Report of the Intergovernmental Panel on Climate Change; Stocker, T.F., Qin, D., Plattner, G.K., Tignor, M.M.B., Allen, S.K., Boschung, J., Nauels, A., Xia, Y., Bex, V., Midgley, P.M., Eds.; Cambridge University Press: Cambridge, UK, 2013; ISBN 978-92-9169-138-8.

3. EEA. Climate Change, Impacts and Vulnerability in Europe 2016: An Indicator-Based Report; Publications Office of the European Union: Luxembourg, 2017; Number 1/2017. [CrossRef]

4. Merz, R.; Blöschl, G. A process typology of regional floods. Water Resour. Res. 2003, 39, SWC510-SWC520. [CrossRef]

5. Alfieri, L.; Thielen, J. A European precipitation index for extreme rain-storm and flash flood early warning. Meteorol. Appl. 2015, 22, 3-13. [CrossRef]

6. Burguet, M.; Taguas, E.V.; Cerdà, A.; Gómez, J. Soil water repellency assessment in olive groves in Southern and Eastern Spain. Catena 2016, 147, 187-195. [CrossRef]

7. Merz, B.; Thieken, A.; Gocht, M. Flood Risk Mapping At The Local Scale: Concepts and Challenges. In Flood Risk Management in Europe: Innovation in Policy and Practice; Begum, S., Stive, M.J.F., Hall, J.W., Eds.; Springer: Dordrecht, The Netherlands, 2007; pp. 231-251. [CrossRef]

8. Nones, M.; Caviedes-Voullième, D. Computational advances and innovations in flood risk mapping. J. Flood Risk Manag. 2020, 13, e12666. [CrossRef]

9. Guo, K.; Guan, M.; Yu, D. Urban surface water flood modelling-A comprehensive review of current models and future challenges. Hydrol. Earth Syst. Sci. 2021, 25, 2843-2860. [CrossRef]

10. Castro, M.; Ortega, S.; de la Asunción, M.; Mantas, J.; Gallardo, J. GPU computing for shallow water flow simulation based on finite volume schemes. Comptes Rendus Mécanique 2011, 339, 165-184. [CrossRef]

11. García-Feal, O.; González-Cao, J.; Gómez-Gesteira, M.; Cea, L.; Domínguez, J.; Formella, A. An accelerated tool for flood modelling based on Iber. Water 2018, 10, 1459. [CrossRef]

12. Caviedes-Voullième, D.; Fernández-Pato, J.; Hinz, C. Performance assessment of 2D Zero-Inertia and Shallow Water models for simulating rainfall-runoff processes. J. Hydrol. 2020, 584, 124663. [CrossRef]

13. Morales-Hernández, M.; Sharif, M.B.; Kalyanapu, A.; Ghafoor, S.; Dullo, T.; Gangrade, S.; Kao, S.C.; Norman, M.; Evans, K. TRITON: A Multi-GPU open source 2D hydrodynamic flood model. Environ. Model Softw. 2021, 141, 105034. [CrossRef]

14. Shaw, J.; Kesserwani, G.; Neal, J.; Bates, P.; Sharifian, M.K. LISFLOOD-FP 8.0: The new discontinuous Galerkin shallow-water solver for multi-core CPUs and GPUs. Geosci. Model Dev. 2021, 14, 3577-3602. [CrossRef]

15. Pilgrim, D.; Chapman, T.; Doran, D. Problems of rainfall-runoff modelling in arid and semiarid regions. Hydrol. Sci. J. 1988, 33, 379-400. [CrossRef]

16. Peral-García, P.; Fernández-Victorio, B.; Ramos-Calzado, P. Serie de Precipitación Diaria en Rejilla Con Fines Climáticos; Agencia Estatal de Meteorología, Ministerio para la Transición Ecológica y el Reto Demográfico: Madrid, Spain, 2017. [CrossRef]

17. Herrera, S.; Fernández, J.; Gutiérrez, J. Update of the Spain02 gridded observational dataset for EURO-CORDEX evaluation: Assessing the effect of the interpolation methodology. Int. J. Climatol. 2016, 36, 900-908. [CrossRef]

18. Yuan, F.; Wang, B.; Shi, C.; Cui, W.; Zhao, C.; Liu, Y.; Ren, L.; Zhang, L.; Zhu, Y.; Chen, T. Evaluation of hydrological utility of IMERG Final run V05 and TMPA 3B42V7 satellite precipitation products in the Yellow River source region, China. J. Hydrol. 2018, 567, 696-711. [CrossRef]

19. Yong, B.; Liu, D.; Gourley, J.; Tian, Y.; Huffman, G.; Ren, L.; Hong, Y. Global view of real-time TRMM multisatellite precipitation analysis: Implications for its successor global precipitation measurement mission. Bull. Am. Meteorol. Soc. 2015, 96, 283-296. [CrossRef]

20. Joyce, R.; Janowiak, J.; Arkin, P.; Xie, P. CMORPH: A method that produces global precipitation estimates from passive microwave and infrared data at high spatial and temporal resolution. J. Hydrometeorol. 2004, 5, 487-503. [CrossRef]

21. Ushio, T.; Sasashige, K.; Kubota, T.; Shige, S.; Okamoto, K.; Aonashi, K.; Inoue, T.; Takahashi, N.; Iguchi, T.; Kachi, M. A Kalman filter approach to the Global Satellite Mapping of Precipitation (GSMaP) from combined passive microwave and infrared radiometric data. J. Meteorol. Soc. Jpn. 2009, 87, 137-151. [CrossRef] 
22. Hong, Y.; Hsu, K.; Sorooshian, S.; Gao, X. Precipitation estimation from remotely sensed imagery using an artificial neural network cloud classification system. J. Appl. Meteorol. Climatol. 2004, 43, 1834-1853. [CrossRef]

23. Goldberg, M.; Kilcoyne, H.; Cikanek, H.; Mehta, A. Joint Polar Satellite System: The United States next generation civilian polar-orbiting environmental satellite system. J. Geophys. Res. Atmos. 2013, 118, 13-463. [CrossRef]

24. Kidd, C.; Kniveton, D.; Todd, M.; Bellerby, T. Satellite rainfall estimation using combined passive microwave and infrared algorithms. J. Hydrometeorol. 2003, 4, 1088-1104. [CrossRef]

25. Farhadi, H.; Najafzadeh, M. Flood Risk Mapping by Remote Sensing Data and Random Forest Technique. Water 2021, $13,3115$. [CrossRef]

26. Notti, D.; Giordan, D.; Caló, F.; Pepe, A.; Zucca, F.; Galve, J. Potential and limitations of open satellite data for flood mapping. Remote Sens. 2018, 10, 1673. [CrossRef]

27. Schumm, S. Geomorphic Implications of Climatic Changes; Introduction to Fluvial Processes; Routledge: New York, NY, USA, 2019; Volume 3, pp. 202-211. [CrossRef]

28. Bohorquez, P. Paleohydraulic Reconstruction of Modern Large Floods at Subcritical Speed in a Confined Valley: Proof of Concept. Water 2016, 8, 567. [CrossRef]

29. Colomina, I.; Molina, P. Unmanned aerial systems for photogrammetry and remote sensing: A review. ISPRS J. Photogramm. Remote Sens. 2014, 92, 79-97. [CrossRef]

30. Cook, K.L. An evaluation of the effectiveness of low-cost UAvs. and structure from motion for geomorphic change detection. Geomorphology 2017, 278, 195-208. [CrossRef]

31. Granados-Bolaños, S.; Quesada-Román, A.; Alvarado, G. Low-cost UAV applications in dynamic tropical volcanic landforms. J. Volcanol. Geotherm. Res. 2021, 410, 107143. [CrossRef]

32. Bohorquez, P.; Moral-Erencia, J. 100 years of competition between reduction in channel capacity and streamflow during floods in the Guadalquivir River (Southern Spain). Remote Sens. 2017, 9, 727. [CrossRef]

33. Bates, P.; De Roo, A. A simple raster-based model for flood inundation simulation. J. Hydrol. 2000, 236, 54-77. [CrossRef]

34. Wood, M.; Hostache, R.; Neal, J.; Wagener, T.; Giustarini, L.; Chini, M.; Corato, G.; Matgen, P.; Bates, P. Calibration of channel depth and friction parameters in the LISFLOOD-FP hydraulic model using medium-resolution SAR data and identifiability techniques. Hydrol. Earth Syst. Sci. 2016, 20, 4983-4997. [CrossRef]

35. Feldman, A. HEC models for water resources system system simulation: Theory and experience. Adv. Hydrosci. 1981, 12, 297-423. [CrossRef]

36. Baker, V.R. Paleoflood hydrology and extraordinary flood events. J. Hydrol. 1987, 96, 79-99. [CrossRef]

37. Bohorquez, P.; Darby, S. The use of one- and two-dimensional hydraulic modelling to reconstruct a glacial outburst flood in a steep Alpine valley. J. Hydrol. 2008, 361, 240-261. [CrossRef]

38. Wyżga, B.; Radecki-Pawlik, A.; Galia, T.; Plesiński, K.; Škarpich, V.; Dušek, R. Use of high-water marks and effective discharge calculation to optimize the height of bank revetments in an incised river channel. Geomorphology 2020, 356, 107098. [CrossRef]

39. Herget, J.; Roggenkamp, T.; Krell, M. Estimation of peak discharges of historical floods. Hydrol. Earth Syst. Sci. 2014, 18 , $4029-4037$. [CrossRef]

40. Bodoque, J.; Díez-Herrero, A.; Eguibar, M.; Benito, G.; Ruiz-Villanueva, V.; Ballesteros-Cánovas, J. Challenges in paleoflood hydrology applied to risk analysis in mountainous watersheds-A review. J. Hydrol. 2015, 529, 449-467. [CrossRef]

41. Wilhelm, B.; Ballesteros-Cánovas, J.; Macdonald, N.; Toonen, W.; Baker, V.; Barriendos, M.; Benito, G.; Brauer, A.; Corella, J.; Denniston, R.; et al. Interpreting historical, botanical, and geological evidence to aid preparations for future floods. WIREs Water 2019, 6, e1318. [CrossRef]

42. Paillou, P.; Lopez, S.; Marais, E.; Scipal, K. Mapping Paleohydrology of the Ephemeral Kuiseb River, Namibia, from Radar Remote Sensing. Water 2020, 12, 1441. [CrossRef]

43. Quesada-Román, A.; Ballesteros-Cánovas, J.; Granados-Bolaños, S.; Birkel, C.; Stoffel, M. Improving regional flood risk assessment using flood frequency and dendrogeomorphic analyses in mountain catchments impacted by tropical cyclones. Geomorphology 2022, 396, 108000. [CrossRef]

44. Brutsaert, W. Hydrology: An Introduction; Cambridge University Press: Cambridge, UK, 2005. [CrossRef]

45. Ruiz-Bellet, J.; Balasch, J.; Tuset, J.; Barriendos, M.; Mazon, J.; Pino, D. Historical, hydraulic, hydrological and meteorological reconstruction of 1874 Santa Tecla flash floods in Catalonia (NE Iberian Peninsula). J. Hydrol. 2015, 524, 279-295. [CrossRef]

46. Bellos, V.; Papageorgaki, I.; Kourtis, I.; Vangelis, H.; Kalogiros, I.; Tsakiris, G. Reconstruction of a flash flood event using a 2D hydrodynamic model under spatial and temporal variability of storm. Nat. Hazards 2020, 101, 711-726. [CrossRef]

47. Olcina-Cantos, J.; Díez-Herrero, A. Technical Evolution of Flood Maps Through Spanish Experience in the European Framework. Cartogr. J. 2021, 2021, 1-14. [CrossRef]

48. Díez-Herrero, A.; Laín-Huerta, L.; Llorente-Isidro, M. A Handbook on Flood Hazard Mapping Methodologies; Number 2 in Geological Hazards/Geotechnics, Geological Survey of Spain; Instituto Geológico y Minero de España: Madrid, Spain, 2009; ISBN 978-84-7840-813-9.

49. Hazenberg, P.; Leijnse, H.; Uijlenhoet, R. Radar rainfall estimation of stratiform winter precipitation in the Belgian Ardennes. Water Resour. Res. 2011, 47. [CrossRef]

50. Barzkar, A.; Najafzadeh, M.; Homaei, F. Evaluation of drought events in various climatic conditions using data-driven models and a reliability-based probabilistic model. Nat. Hazards 2021. [CrossRef] 
51. Anguelov, D.; Dulong, C.; Filip, D.; Frueh, C.; Lafon, S.; Lyon, R.; Ogale, A.; Vincent, L.; Weaver, J. Google Street View: Capturing the World at Street Level. Computer 2010, 43, 32-38. [CrossRef]

52. Kalnay, E.; Kanamitsu, M.; Kistler, R.; Collins, W.; Deaven, D.; Gandin, L.; Iredell, M.; Saha, S.; White, G.; Woollen, J.; et al. The NCEP/NCAR 40-Year Reanalysis Project. Bull. Am. Meteorol. Soc. 1996, 77, 437-472. [CrossRef] 